Revista Brasileira de Cartografia

ISSN 1808-0936 | https://doi.org/10.14393/revbrascartogr

Sociedade Brasileira de Cartografia, Geodésia, Fotogrametria e Sensoriamento Remoto

\title{
Modelo Linear de Mistura Espectral: Conceitos Teóricos, Algoritmos e Aplicações em Estudos na Amazônia Legal
}

\author{
Linear Spectral Mixing Model: Theoretical Concepts, Algorithms and Applications in \\ Studies in the Legal Amazon
}

Yosio Edemir Shimabukuro ${ }^{1}$, Andeise Cerqueira Dutra ${ }^{2}$ e Egidio Arai ${ }^{3}$

1 Instituto Nacional de Pesquisas Espaciais (INPE), Divisão de Observação da Terra e Geoinformática (DIOTG), São José dos Campos, SP, Brasil, E-mail. yosio.shimabukuro@inpe.br

ORCID: https:// orcid.org/0000-0002-1469-8433

2 Instituto Nacional de Pesquisas Espaciais (INPE), Divisão de Observação da Terra e Geoinformática (DIOTG), São José dos

Campos, SP, Brasil, E-mail. andeise.dutra@inpe.br.

ORCID: https:// orcid.org/0000-0002-4454-7732

3 Instituto Nacional de Pesquisas Espaciais (INPE), Divisão de Observação da Terra e Geoinformática (DIOTG), São José dos

Campos, SP, Brasil, E-mail. egidio.arai@inpe.br

ORCID: https:// orcid.org/0000-0003-1994-5277

Resumo: Este trabalho apresenta uma revisão sobre o Modelo Linear de Mistura Espectral e suas aplicações na Amazônia Legal. Os estudos sobre mistura espectral iniciaram na década de 1970, motivada pelo problema na estimativa de áreas obtida por interpretação automática. O pixel era classificado ou não baseado na máxima probabilidade desse pixel pertencer a determinada classe, superestimando ou subestimando esta classe de acordo com a decisão tomada. Surgiu então o interesse no estudo da mistura espectral dentro do pixel. A resposta de cada pixel pode ser considerada como uma combinação linear das respostas espectrais de cada componente que está na mistura desse pixel. Dessa forma, conhecendo-se as respostas espectrais dos componentes, podemos obter as proporções desses componentes (imagens fração). Neste trabalho são apresentados os conceitos teóricos que motivaram o desenvolvimento desse modelo, e são descritos os algoritmos (Mínimos Quadrados com Restrição, Mínimos Quadrados Ponderados, Principais Componentes) desenvolvidos na década de 1980. Com a disponibilidade desses algoritmos em softwares de processamento de imagens digitais na década de 1990, aumentou o número de trabalhos que fazem uso dessa técnica no Brasil e no mundo. As imagens fração foram utilizadas para automatizar o Projeto PRODES (Monitoramento do Desmatamento da Floresta Amazônica Brasileira por Satélite) que foi o primeiro projeto operacional sistemático de Sensoriamento Remoto orbital. A seguir é apresentada a utilização das imagens fração em estudos realizados na Amazônia brasileira. Além disso, é apresentada uma perspectiva de uso das imagens fração em estudos globais. Em conclusão, o Modelo Linear de Mistura Espectral tem contribuído para o desenvolvimento de várias pesquisas e aplicações de Sensoriamento Remoto devido as suas características de redução de dados e por realçar os alvos de interesse nas imagens.

Palavras-chave: Mínimos Quadrados com Restrição. Desmatamento. Corte Seletivo. Queimada. Uso e Cobertura da Terra.

Abstract: This paper presents a review of the Linear Spectral Mixing Model and its applications in the Legal Amazon.
Studies on spectral mixture began in the 1970s, motivated by the problem of area estimation obtained by automatic
interpretation. The pixel was classified or not based on the maximum probability of this pixel to belong to a given class,
then overestimating or underestimating this class according to the decision made. Thus, interest in the study of the
spectral mixture within the pixel arose. The response of each pixel can be considered as a linear combination of the
spectral responses of each component that is within the pixel. Thus, knowing the spectral responses of the components,
we can obtain the proportions of these components (fraction images). This paper presents the theoretical concepts that
motivated the development of this model, and the algorithms (Constrained Least Squares, Weighted Least Squares,
Principal Components) developed in the 1980s are described. With the availability of these algorithms in the digital
image processing softwares in the 1990s, the number of studies using this technique increased in Brazil and worldwide.
The fraction images were used to automate the PRODES Project (Monitoring deforestation of the Brazilian Amazon
Forest by Satellite) which was the first systematic operational project of orbital Remote Sensing. Following the use of
fraction images in studies conducted in the Brazilian Amazon are presented. In addition, a perspective of use of fraction
images for global studies is presented. In conclusion, the Linear Spectral Mixture Model has contributed to the
development of several research and applications of Remote Sensing due to its data reduction characteristics and by
highlighting the targets of interest in the images. 
Keywords: Constrained Least Squares. Deforestation. Selective Logging. Burning. Land Use and Land Cover.

\section{INTRODUÇÃO}

O fenômeno de "mistura espectral" tem sido levado em consideração por alguns investigadores no âmbito do sensoriamento remoto (HORWITZ et al., 1971; DETCHMENDY; PACE, 1972; HEIMES, 1977; SHIMABUKURO, 1987). Geralmente o problema surge quando se tenta classificar corretamente um pixel que contém uma mistura de materiais na superfície como solo, vegetação, rochas, água e outros. A não uniformidade da maioria dos cenários naturais geralmente resulta em um grande número de componentes na mistura. O problema de mistura espectral se torna mais crítico para técnicas de processamento digital do que para interpretação visual por intérpretes treinados. Os intérpretes utilizam basicamente três elementos padrão fundamentais - espectral, espacial, e característica contextual (PANIZZA; FONSECA, 2011) - para extrair informações de imagens aéreas e provenientes de satélites, enquanto que a maior parte das técnicas de análises digitais se baseiam predominantemente nas características espectrais dos pixels.

O processo de mistura espectral pode ocorrer independentemente da resolução espacial do sensor, portanto, o problema de pixel com mistura não é resolvido simplesmente aumentando a resolução espacial (KESHAVA; MUSTARD, 2002). Por exemplo, em imagens de alta resolução espacial do dossel de uma floresta, elementos como sombra e lacunas tornam-se aparentes, colaborando para a mistura dentro do pixel na imagem.

Várias formulações matemáticas para resolver a mistura espectral de materiais dentro de pixels têm sido relatadas na literatura. Horwitz et al. (1971) usaram um algoritmo de programação não linear para extrair os componentes da mistura. O procedimento de mínimos quadrados com restrições foi proposto por Detchmendy e Pace (1972), enquanto Hallum (1972) expandiu o conjunto de soluções de Detchmendy e Pace (1972) incorporando restrições nas proporções.

No entanto, o modelo de mistura espectral não era realmente empregado no sensoriamento remoto até meados da década de 1980 (SMITH et al., 1985; ADAMS et al., 1986; SHIMABUKURO, 1987). Desde então, o interesse em mistura espectral (linear e não linear) aumentou bastante e vários trabalhos têm sido desenvolvidos utilizando esta técnica (BOARDMAN, 1993; ROBERTS et al., 1993; FARRAND et al., 1994; ATKINSON et al., 1997; BASTIN, 1997; FOODY et al., 1997; NOVO; SHIMABUKURO, 1994; SHIMABUKURO; SMITH, 1995; ROSIN, 2001; GARCÍA-HARO et al., 2005; ALCÂNTARA et al., 2009). Os modelos desenvolvidos têm sido aplicados em imagens obtidas pelos diversos satélites de observação da Terra. Esses modelos estimam as proporções dos componentes dentro dos pixels gerando imagens fração correspondentes aos componentes desses pixels. De maneira geral a mistura do pixel é formada comumente pelos componentes de alto albedo e baixo albedo, podendo então representar respectivamente, as imagens fração de solo, vegetação e sombra. Essas imagens fração têm sido utilizadas em várias áreas de pesquisa como em recursos florestais, áreas agrícolas, áreas urbanas, áreas inundadas, etc. Além disso, essas imagens fração foram importantes para a criação de projetos operacionais de estimativa de áreas desflorestadas (PRODES) (SHIMABUKURO et al., 1998), de detecção de áreas desflorestadas em tempo quase real (DETER) (ANDERSON et al., 2005; SHIMABUKURO et al., 2006), e estão sendo utilizadas em vários trabalhos de pesquisa na Amazônia Legal.

Nesse contexto, o objetivo deste trabalho é apresentar uma revisão sobre o Modelo Linear de Mistura Espectral. Dessa maneira, são apresentados os conceitos teóricos, os algoritmos matemáticos, e exemplos de aplicações na Amazônia Legal.

\section{CONCEITOS TEÓRICOS}

O brilho registrado em imagens de satélite é uma soma integrada dos brilhos de todos alvos dentro do campo de visão instantânea (IFOV) dos sensores. Assim, a radiação detectada é causada por uma mistura de vários materiais diferentes dentro dos pixels da imagem (SHIMABUKURO, 1987; SHIMABUKURO; SMITH, 1991). Desta forma, inúmeros materiais diferentes muitas vezes contribuem para o espectro registrado 
em um pixel de uma imagem proveniente de satélites. Dessa maneira, a identificação dos materiais constituintes individuais presentes na mistura e nas proporções em que elas aparecem é importante para analisar as imagens, visto que a mistura poderá resultar em superestimativa ou subestimativa de área na classificação automática, de acordo com a maior ou menor probabilidade desse pixel pertencer a um desses materiais considerados (SHIMABUKURO, 1987).

A mistura de diferentes materiais ou objetos contidos "dentro" do pixel no momento de medir a intensidade do fluxo radiante por um sensor, acontece quando diferentes objetos são instantaneamente visualizados em uma porção da terra com dimensões bem definidas. Sabe-se que o fluxo de radiação originado pela reflexão da radiação incidente é, na verdade, uma mistura de diferentes fluxos de radiação que resultará em uma única medida de intensidade em cada região espectral do espectro eletromagnético em que o sensor é capaz de atuar.

O conceito de mistura espectral foi discutido por Horwitz et al. (1971), Detchmendy e Pace (1972), Ranson (1975) e Heimes (1977), entre outros. A mistura espectral pode ocorrer em dois casos: 1) quando os materiais (ou objetos) são menores do que o tamanho do pixel, ou seja, o fluxo de radiação detectado pelo sensor é composto por uma mistura de radiação de todos os materiais dentro do pixel; e 2) quando o pixel se sobrepõe à borda entre dois ou mais materiais ou objetos maiores do que seu tamanho (SHIMABUKURO, 1987). Em ambos os casos, os sinais registrados pelo sensor não são representativos de nenhum dos materiais presentes. Assim, a mistura espectral é o procedimento pelo qual o espectro medido de um pixel com mistura é decomposto em uma coleção de espectros constituintes, ou endmembers, e um conjunto de proporções ou abundâncias correspondentes que indicam a proporção de cada endmember presente no pixel (KESHAVA, 2003).

O processo de mistura pode ser considerado linear ou não linear. A combinação vai ser basicamente linear se os endmembers em um pixel aparecerem em padrões espacialmente segregados. Neste caso, a dispersão e absorção da radiação eletromagnética incidente em qualquer região na superfície é dominada por um único componente na superfície. Assim, o espectro de um pixel misturado pode ser considerado uma combinação linear do espectro ponderado pela cobertura de área fracionada de cada endmember dentro do pixel (HAPKE, 1993). No entanto, se os componentes de interesse estão em uma associação circunstancial, a radiação eletromagnética normalmente interagirá com mais do que um componente (como grãos de areia de diferentes composições em uma praia) e o processo de mistura entre esses diferentes componentes será não linear, como um resultado de interação de dispersão múltipla. Um exemplo de mistura não linear é a intercalação de diferentes tipos de vegetação em copas de árvores (ROBERTS et al., 1993).

A abordagem linear foi demonstrada em inúmeras aplicações por ser considerada uma técnica útil para interpretar a variabilidade em dados de sensoriamento remoto e uma maneira poderosa de converter informações espectrais em produtos de dados com significado físico, como abundância de materiais na superfície terrestre (KESHAVA; MUSTARD, 2002).

Dada a importância do modelo linear de mistura espectral e a gama de aplicações, vários trabalhos de revisão têm aparecido na literatura descrevendo os algoritmos existentes para gerar as imagens fração (ADAMS et al., 1995; ICHOKU; KARNIELI; 1996; KESHAVA; MUSTARD, 2002; PLAZA et al., 2002; KESHAVA, 2003; PLAZA et al., 2004; ADAMS; GILLESPIE, 2006; QUINTANO et al., 2012).

Geralmente, o modelo linear de mistura espectral pode ser escrito como a Eq. (1):

$$
r_{i}=\sum_{j=1}^{m} x_{j} a_{i, j}+e_{i}
$$

sendo:

$r_{i}=$ reflectância espectral do pixel para a i-ésima banda espectral;

$a_{i j}=$ reflectância espectral do j-ésimo componente no pixel para a i-ésima banda espectral;

$x_{j}=$ valor do j-ésimo componente no pixel;

$e_{i}=$ erro para a i-ésima banda espectral;

$j=1,2, \ldots, m(m=$ número de componentes considerados no pixel); 
$i=1,2, \ldots, n$ ( $n=$ número de bandas espectrais dos sensores).

Como mencionado anteriormente, este modelo assume que a resposta espectral (na Eq. 1, expressa como reflectância) dos pixels são combinações lineares das respostas espectrais dos componentes dentro do pixel. Para resolver a Eq. 1, é necessário ter a reflectância espectral dos pixels em cada banda $\left(r_{i}\right)$ e a reflectância espectral de cada componente $\left(a_{i j}\right)$ em cada banda para estimar os valores de proporção, ou viceversa.

Para a solução do sistema de equações lineares que representa o modelo de mistura espectral em questão, existem várias abordagens matemáticas baseadas no método dos mínimos quadrados. A seguir serão apresentados três algoritmos disponíveis nos softwares atuais de processamento de imagens (SPRING, ENVI e PCI) (SHIMABUKURO; PONZONI, 2017).

\section{ALGORITMOS MATEMÁTICOS}

As porcentagens de cada objeto dentro de um pixel podem assumir várias dimensões, dependendo da resolução espacial de cada sensor. Essas proporções são calculadas aplicando modelos matemáticos. Neste trabalho, serão apresentados os modelos lineares, mas é importante destacar que a linearidade pode não ser a única maneira de descrever a participação de cada objeto em um pixel. Os modelos lineares de mistura espectral (MLME) serão descritos por serem amplamente utilizados pelos pesquisadores com resultados consistentes.

Seguindo essa abordagem, a resposta espectral em cada pixel, em qualquer banda espectral de um sensor, pode ser imaginada como uma combinação linear das respostas espectrais de cada componente presente na mistura. Assim, cada pixel da imagem, que pode assumir qualquer valor dentro da faixa de nível de cinza da imagem, contém informações sobre a proporção (quantidade) e a resposta espectral de cada componente dentro de um elemento de resolução espacial (pixel) no solo. Portanto, para qualquer imagem multiespectral gerada por qualquer sistema sensor, considerando o conhecimento da proporção de componentes, será possível estimar a resposta espectral de cada um desses componentes. Da mesma forma, se essa resposta for conhecida, a proporção de cada componente na mistura pode ser estimada. Essa característica ajuda na análise de diferentes sensores com diversas resoluções espaciais. Por exemplo, é possível gerar imagens fração a partir de um sensor com alta resolução espacial (pixels com pequenas dimensões) e, com base nessas proporções, estimar as respostas espectrais dos objetos presentes nos pixels gerados por um sensor de média resolução espacial, e depois gerar as imagens de fração para essas imagens de sensor de moderada e baixa resolução espacial (SHIMABUKURO; SMITH, 1995; DUTRA et al., 2019).

O modelo linear de mistura espectral é um sistema de equações, com uma equação para cada banda considerada do sensor. Por exemplo, para o sensor MSS (Multi Spectral Scanner), a bordo dos satélites Landsat 1 a 5, existem quatro equações, correspondentes às bandas 4, 5, 6 e 7, enquanto para o sensor TM (Thematic Mapper) a bordo dos satélites Landsat 4 e 5 existem seis equações, correspondentes às bandas 1, 2, 3, 4, 5 e 7, levando em consideração apenas o espectro óptico solar. É importante ter em mente que não é necessário usar todas as bandas disponíveis, mas deve-se obedecer à condição de que o número de espectros de referência (ou pixels puros) sempre seja menor que o número de bandas espectrais. Dessa maneira, algoritmos matemáticos são necessários para a solução do sistema de equações formado pela resposta espectral do pixel, que é a função da proporção de cada espectro de referência (ou pixels puros) ponderado pela respectiva resposta espectral do componente. A seguir serão apresentados três algoritmos matemáticos: Mínimos Quadrados com Restrição, Mínimos Quadrados Ponderados e Componentes Principais (SHIMABUKURO; PONZONI, 2017).

\subsection{Mínimos Quadrados com Restrição}

Este método estima a proporção de cada componente dentro do pixel, minimizando a soma dos erros ao quadrado. Os valores da proporção obtidos por este algoritmo devem resultar em números não negativos (significado físico) e o somatório igual a 1. Para resolver esse problema, foi desenvolvido um método de solução quase fechada (por exemplo, um método que encontra a solução fazendo aproximações que satisfazem essas restrições). Como exemplo, o método proposto será apresentado para o caso de três componentes $(m=3)$ 
dentro do pixel. É importante lembrar que esse modelo pode ser desenvolvido para um número maior de endmembers, mas que a solução se tornará cada vez mais complexa. Assim, o modelo de mistura, escrito na Eq. (1), pode ser reescrito como a Eq. (2):

$$
e_{i}=r_{i}-\sum_{j=1}^{m} x_{j} a_{i, j}
$$

Neste caso vamos utilizar $n=4$ bandas espectrais e $m=3$ componentes dentro do pixel. A função a ser minimizada pode ser escrita como a Eq. (3) ou a Eq. (4):

$$
F=\sum e_{i}^{2}
$$

ou

$$
\begin{gathered}
e_{1}{ }^{2}+e_{2}{ }^{2}+e_{3}{ }^{2}+e_{4}{ }^{2}= \\
E_{1} x_{1}{ }^{2}+E_{2} x_{2}{ }^{2}+E_{3} x_{3}{ }^{2}+E_{4} x_{1} x_{2}+E_{5} x_{1} x_{3}+E_{6} x_{2} x_{3}+E_{7} x_{1}+E_{8} x_{2}+E_{9} x_{3}+E_{10}
\end{gathered}
$$

Os valores dos coeficientes $E_{1}$ a $E_{10}$ são mostrados no Quadro 1.

$$
\begin{aligned}
& E_{1}=a_{11}{ }^{2}+a_{21}{ }^{2}+a_{31}{ }^{2}+a_{41}{ }^{2} \\
& E_{2}=a_{12} 2^{2}+a_{22} 2^{2}+a_{32}+a_{42}{ }^{2} \\
& E_{3}=a_{13}+a_{23}+a_{33}+a_{43}{ }^{2} \\
& E_{4}=2 x\left(a_{11} a_{12}+a_{21} a_{22}+a_{31} a_{32}+a_{41} a_{42}\right) \\
& E_{5}=2 x\left(a_{11} a_{13}+a_{21} a_{23}+a_{31} a_{33}+a_{41} a_{43}\right) \\
& E_{6}=2 x\left(a_{12} a_{13}+a_{22} a_{23}+a_{32} a_{33}+a_{42} a_{43}\right) \\
& E_{7}=-2 x\left(a_{11} r_{1}+a_{21} r_{2}+a_{31} r_{3}+a_{41} r_{4}\right) \\
& E_{8}=-2 x\left(a_{12} r_{1}+a_{22} r_{2}+a_{32} r_{3}+a_{42} r_{4}\right) \\
& E_{9}=-2 x\left(a_{13} r_{1}+a_{23} r_{2}+a_{33} r_{3}+a_{43} r_{4}\right) \\
& E_{10}=r_{1}^{2}+r_{2}^{2}+r_{3}^{2}+r_{4}^{2}
\end{aligned}
$$

Fonte: Shimabukuro e Ponzoni (2017).

Considere a primeira restrição: $x_{1}+x_{2}+x_{3}=1$ ou $x_{3}=1-x_{1}-x_{2}$. Substituindo essa restrição na Eq. (4), a função a ser minimizada passa a ser escrita como a Eq. (5):

$$
\begin{gathered}
e_{1}{ }^{2}+e_{2}{ }^{2}+e_{3}{ }^{2}+e_{4}{ }^{2}= \\
A_{1} x_{1}{ }^{2}+A_{2} x_{2}{ }^{2}+A_{3} x_{1} x_{2}+A_{4} x_{1}+A_{5} x_{2}+A_{6}
\end{gathered}
$$

Os valores dos coeficientes $A_{l}$ a $A_{6}$ são mostrados no Quadro 2 . 
Quadro 2 - Valores dos coeficientes $A$ da Eq. (5).

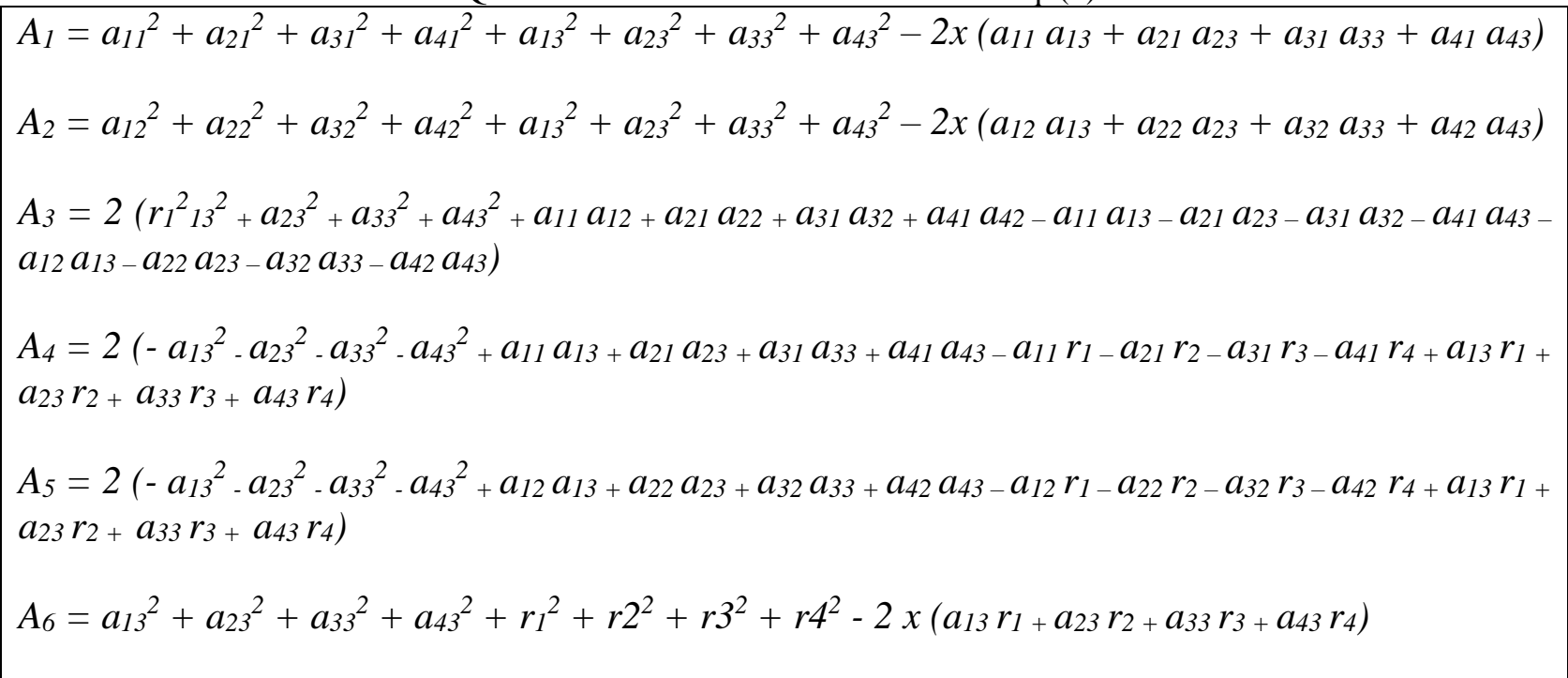

Fonte: Shimabukuro e Ponzoni (2017).

Dessa maneira a função a ser minimizada é reescrita como na Eq. (6):

$$
F=A_{1} x_{1}{ }^{2}+A_{2} x_{2}{ }^{2}+A_{3} x_{1} x_{2}+A_{4} x_{1}+A_{5} x_{2}+A_{6}
$$

em que os coeficientes $A_{l}$ a $A_{6}$ são funções dos valores espectrais, $a_{i j}$ (valores de resposta dos endmembers) e $r_{i}$ (valores de resposta do pixel).

Para solucionar esse problema, faz-se necessário encontrar um valor mínimo dentro da área definida pelas retas: $0 \leq x_{1} \leq a, 0 \leq x_{2} \leq b$, e $\frac{x_{1}}{a}+\frac{x_{2}}{b}=1$, em que $a=b=1$ (Figura 1). Considerando a função a ser minimizada, de maneira a encontrar o valor mínimo, as derivadas parciais são calculadas e igualadas a zero, como escrita na Eq. (7) e na Eq. (8):

$$
\begin{aligned}
& \frac{d F}{d x_{1}}=2 A_{1} x_{1}+A_{2} x_{2}+A_{4}=0 \\
& \frac{d F}{d x_{2}}=2 A_{2} x_{2}+A_{3} x_{1}+A_{5}=0
\end{aligned}
$$

Resolvendo para $x_{1}$ e $x_{2}$, escrito como a Eq. (9) e a Eq. (10), respectivamente:

$$
\begin{aligned}
& x_{1}=\frac{\left(A_{3} A_{5}-2 A_{2} A_{4}\right)}{\left(4 A_{1} A_{2}-A_{3}^{2}\right)} \\
& x_{2}=\frac{\left(A_{3} A_{4}-2 A_{1} A_{5}\right)}{\left(4 A_{1} A_{2}-{A_{3}}^{2}\right)}
\end{aligned}
$$

Figura 1 - Região que atende às restrições para o número de componentes igual a três.

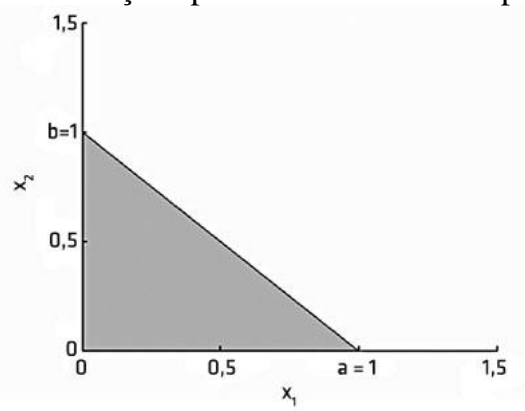

Fonte: Shimabukuro e Ponzoni (2017). 
Então, existem cinco situações possíveis, as quais são descritas a seguir.

- Situação 1, em que o valor mínimo está dentro da região de interesse. Então, essa é a solução final e $x_{3}=1-x_{1}-x_{2}$;

- Situação 2, em que o valor mínimo está fora da região e $x_{1}$ e $x_{2}$ são positivos. Nesse caso, o valor mínimo restrito é procurado na reta definida por $x_{1}+x_{2}=1$ (isto é, $x_{3}=0$ ). Agora, fazendo $x_{2}=1$ $-x_{l}$, a função a ser minimizada pode ser escrita como a Eq. (11):

$$
F=\left(A_{1}+A_{2}-A_{3}\right) x_{1}^{2}+\left(A_{3}+A_{4}-A_{5}-2 A_{2}\right) x_{1}+\left(A_{2}+A_{5}+A_{6}\right)
$$

O valor mínimo será obtido, como pode ser escrito na Eq. (12) e na Eq. (13), por:

$$
\frac{d F}{d x_{1}}=2\left(A_{1}+A_{2}-A_{3}\right) x_{1}+\left(A_{3}+A_{4}-A_{5}-2 A_{2}\right)=0
$$

Então:

$$
x_{1}=\frac{-\left(A_{3}+A_{4}-A_{5}-2 A_{2}\right)}{\left(2\left(A_{1}+A_{2}-A_{3}\right)\right)}
$$

Se $x_{1}>1$, fazer $x_{1}=1$, ou, se $x_{1}<0$, fazer $x_{1}=0$ e $x_{2}=1-x_{1}$;

- Situação 3, em que o valor mínimo está fora da região e $x_{1}$ é negativo e $x_{2}$ é positivo. Nesse caso, fazendo $x_{1}=0$, a função a ser minimizada torna-se, como pode ser escrito na Eq. (14):

$$
F=A_{2} x_{2}^{2}+A_{5} x_{2}+A_{6}
$$

Resolvendo para achar o mínimo, $x_{2}=\frac{-A_{5}}{2 A_{2}}$. Se $x_{2}>1$, então fazer $x_{2}=1$, ou, se $x_{2}<0$, fazer $x_{2}=0$ e $x_{3}$ $=1-x_{2} ;$

- Situação 4, em que o valor mínimo está fora da região e $x_{1}$ e $x_{2}$ são negativos. Nesse caso, $x_{1}$ e $x_{2}$ são igualados a zero e $x_{3}=1$;

- Situação 5, em que o valor mínimo está fora da região e $x_{1}$ é positivo e $x_{2}$ é negativo. Nesse caso, fazendo $x_{2}=0$, a função a ser minimizada torna-se, como escrito na Eq. (15):

$$
F=A_{1} x_{1}^{2}+A_{4} x_{1}+A_{6}
$$

Resolvendo para encontrar o mínimo, $x_{l}=\frac{-A_{4}}{2 A_{1}}$. Se $x_{l}>1$, então $x_{l}=1$, ou, se $x_{l}<0$, então $x_{l}=0$ e $x_{3}$ $=1-x_{1}$.

\subsection{Mínimos Quadrados Ponderados}

Considere a curva que ajusta os dados no formato escrito na Eq. (16):

$$
R=f\left(A, x_{1}, x_{2}, \ldots, x_{m}\right)=x_{1} f(A)+x_{2} f(A)+\ldots+x_{m} f(A)
$$

onde a variável dependente $R$ é linear em relação a $x_{1}, x_{2}, \ldots, x_{m}$.

Embora existam muitas ramificações e abordagens para o ajuste de curvas, o método dos mínimos quadrados pode ser aplicado a uma ampla variedade de problemas de ajuste de curvas envolvendo a forma linear com valores indeterminados. Os valores são determinados minimizando a soma dos erros ao quadrado (resíduos). A solução obtida por esse método é matematicamente possível, mas pode ser fisicamente inaceitável (algumas restrições estão envolvidas: os valores não devem ser negativos e a soma deve ser igual 
a 1). Então, torna-se um problema de mínimos quadrados restritos, e as equações de restrições devem ser adicionadas. Para resolver esse problema, é necessário aplicar os conceitos de mínimos quadrados ponderados.

Às vezes, as informações obtidas em um experimento podem ser mais precisas do que aquelas decorrentes de outras fontes de informações relacionadas ao mesmo experimento. Em outros casos, é conveniente usar algumas informações adicionais (conhecimento anterior) para tornar a solução fisicamente relevante. Nesses casos, pode ser desejável atribuir um "peso" maior às informações consideradas mais precisas ou mais importantes para o problema. Dar determinados pesos (por exemplo, informações adicionais) é desejável para aproximar a solução do significado físico e obter uma solução aceitável.

Nesse caso, $x_{1}+x_{2}+\ldots+x_{m}=1$ e $0 \leq x_{1}, x_{2}, \ldots, x_{m} \leq 1$ são as condições que devem ser atendidas para obter uma solução aceitável. Então, $r+1$ equações são adicionadas ao sistema da Eq. 10: uma correspondente à soma condicional de proporções igual a $1\left(x_{1}+x_{2}+\ldots+x_{m}=1\right)$ e r equações correspondentes à condição de que as proporções não sejam negativas $\left(0 \leq x_{j} \leq 1, \mathrm{j}=1,2, \ldots, m\right)$. Para resolver esse problema, quando as restrições não são atendidas, é aplicada uma matriz diagonal $\mathrm{W}$ contendo valores de pesos associados ao sistema de equações a serem resolvidas. Inicialmente, os primeiros valores atribuídos são iguais a 1, ao longo da matriz diagonal $\mathrm{W}$, significando que as equações são igualmente importantes para a solução do problema. $\mathrm{O}$ valor muito alto atribuído à diagonal correspondente à primeira restrição (soma de $x_{j}=1$ ) indica que essa equação deve ser rigorosamente satisfeita. Portanto, se os valores de $x_{j}$ são satisfeitos, ou seja, se estão no intervalo entre 0 e 1 , a solução final foi encontrada. Caso contrário, é preciso usar um processo iterativo para colocar todos os $x_{j}$ dentro do intervalo entre 0 e 1 . Isso é conseguido por um aumento gradual dos pesos, que são inicialmente zero, correspondendo às $m$ equações mais recentes relacionadas à restrição de que as proporções não devem ser negativas. A solução para esse problema é encontrada minimizando a quantidade: $w_{1} e_{1}^{2}+w_{2} e_{2}^{2}+\ldots+w(n+m+1)$ e $(n+m+1)^{2}$, onde $w_{1}$, $w_{2}$, etc. são os fatores de peso e $e_{1}, e_{2}$, etc. são os valores de erro para cada equação.

A implementação desse método baseia-se no algoritmo de eliminação e substituição gaussiano, descrito em livros didáticos de análise numérica, como Burden, Faires e Reynolds (1981).

\subsection{Componentes Principais}

Dada uma imagem que consiste em um número de pixels com medidas em várias bandas espectrais, é possível modelar cada resposta espectral de cada pixel como uma combinação linear de um número finito de componentes, como pode ser escrito na Eq. (17).

$$
\begin{aligned}
d n_{1}=f_{1} e_{1,1}+\ldots+f_{n} e_{1, m} & \text { banda } 1 \\
d n_{2}=f_{1} e_{2,1}+\ldots+f_{n} e_{2, m} & \text { banda } 2 \\
\ldots & \\
d n_{p}=f_{1} e_{p, 1}+\ldots+f_{n} e_{p, m} & \text { banda } p
\end{aligned}
$$

sendo:

$d n_{i}=$ resposta espectral para a banda $i$ do pixel;

$e_{i j}=$ resposta espectral do componente puro $j$ na banda $i$;

$f_{j}=$ fração desconhecida do componente puro $j$;

$m=$ número de componentes puros;

$p=$ número de bandas.

Dessa maneira, a equação pode estar na forma de matriz, escrita como a Eq. (18):

$$
d n=e f
$$

Uma restrição linear é adicionada, porque a soma das frações de qualquer pixel deve ser igual a 1; portanto, é preciso aumentar o vetor $d n$ com uma linha de valores 1 . Isso se torna um conjunto de equações $p$ 
+1 em $m$ incógnitas. Como o número de componentes puros é geralmente menor que o número de bandas espectrais, as equações podem ser resolvidas por qualquer técnica. A solução descrita usa a análise de Componentes Principais (PCA) para reduzir a dimensionalidade do conjunto de dados. A matriz do componente puro é transformada em um espaço PCA usando o número apropriado de autovetores, os dados de pixel são transformados em espaço de PCA, as soluções são encontradas, e as frações resultantes são armazenadas (SMITH et al., 1985).

O método dos mínimos quadrados ponderados e o método dos componentes principais são recomendados para os casos em que o número de componentes espectrais na mistura é maior do que três (SHIMABUKURO; PONZONI, 2017).

\section{SELEÇÃO DOS ENDMEMBERS}

Para gerar as imagens frações, é necessário escolher os componentes puros (endmembers) para aplicar qualquer algoritmo matemático disponível. Definido explicitamente, o endmember é apenas um componente que faz parte da mistura espectral, ou seja, que está contido no pixel. Dessa forma, é necessário escolher os endmembers que fazem sentido para a interpretação da imagem considerada e que também atendam aos critérios da fração de acordo com as equações da mistura espectral. Às vezes é fácil escolher esses endmembers quando o comportamento espectral dos alvos já é conhecido para a área que está sendo estudada. Isso ocorre em áreas que já são estudadas há algum tempo, como por exemplo, quando as mudanças no ambiente estão sendo monitoradas. Por outro lado, é necessário realizar experimentos para encontrar os endmembers adequados sempre que as cenas forem desconhecidas ou quando for necessário extrair informações específicas das imagens.

Há duas maneiras de selecionar os endmembers: extraindo os valores espectrais diretamente das imagens ou através da coleta de dados obtidos no laboratório e/ou no campo utilizando espectroradiômetros. Os endmembers derivados das imagens são chamados endmembers de imagem, enquanto os selecionados a partir de dados de laboratório e/ou no campo são chamados endmembers de referência. O mais conveniente é selecionar os endmembers diretamente das imagens que estão sendo estudadas pelo simples motivo de que o espectro do endmember extraído da imagem pode ser usado sem calibração. Por outro lado, os espectros obtidos em laboratório ou em campo apresentam valores de fatores de reflectância. Como conhecido, as imagens orbitais estão, em princípio, disponíveis no formato ND (Número Digital). Dessa forma, os endmembers de referência (fatores de reflectância) estariam em escala ou em uma unidade de medida diferente daquela adotada pelas imagens (NDs), o que interferiria na aplicação do modelo de mistura. O procedimento correto seria converter os NDs das imagens em fatores de reflectância da superfície, com correção atmosférica, a fim de ter compatibilidade na unidade dos dois conjuntos de dados, como já ocorre atualmente com a disponibilidade pela grande maioria dos produtos orbitais gratuitos (exemplo: série Landsat e MODIS).

Os endmembers de imagem, embora convenientes por não precisarem de calibração, nem sempre funcionam em modelos de mistura. Para funcionar bem, é necessário ter uma boa concordância entre a escala de pixels e a escala na qual os materiais ocorrem relativamente puros no terreno. Na melhor das hipóteses, pode ser usado o endmember de imagem se a imagem de estudo apresentar pelo menos alguns pixels totalmente ocupados por um único material na superfície terrestre.

Pode-se concluir de uma maneira mais ou menos intuitiva que a definição do número e a seleção dos endmembers a serem considerados são essenciais para o sucesso da aplicação do modelo de mistura. No entanto, sabe-se que, no mundo real, o terreno pode ser espectralmente complexo. Uma razão pela qual as imagens podem ser bem modeladas por poucos espectros de endmembers é devido ao fato de que alguns dos endmembers em potencial estão em pequenas proporções na superfície da Terra em comparação com os principais endmembers considerados na mistura de um pixel.

Ao considerar a utilização dos endmembers da imagem, supõe-se que em imagens de alta e média resolução espacial haja uma maior probabilidade de encontrar pixels puros ou pixels que incluem um único componente disponível na imagem. Entretanto, em imagens de resolução espacial moderada e baixa, a natureza mista dos pixels limita essa abordagem devido à dificuldade ou mesmo à impossibilidade de obter pixels puros (SHIMABUKURO; SMITH, 1995; DE FREITAS et al., 2008). Particularmente em estudos em escala global 
ou regional, a determinação desses endmembers permanece um desafio (MEYER; OKIN, 2015). Nessa perspectiva, alguns estudos propõem estimar as respostas espectrais dos endmembers em imagens de baixa resolução espacial, a partir das proporções obtidas das imagens de maior resolução espacial (Figura 2) utilizando modelos de regressão (SHIMABUKURO; SMITH, 1995; DE FREITAS et al., 2008; DUTRA et al., 2019). Assumindo que a reflectância espectral de um pixel pode ser obtida como uma combinação linear das respostas de cada elemento contido dentro dele, cada pixel contém informações sobre a proporção e a resposta espectral de cada componente (SHIMABUKURO; SMITH, 1991).

Figura 2 - Representação de um pixel com resolução espacial de $1 \mathrm{~km}$ e a mesma área de abrangência em pixels de 100 m obtidas do mesmo satélite PROBA-V.

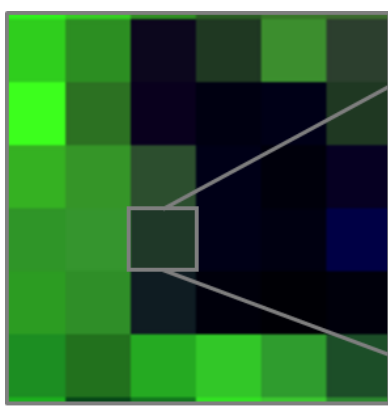

$1 \mathrm{~km}$

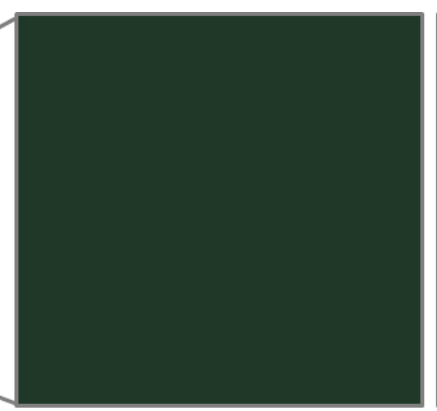

$1 \mathrm{~km}$

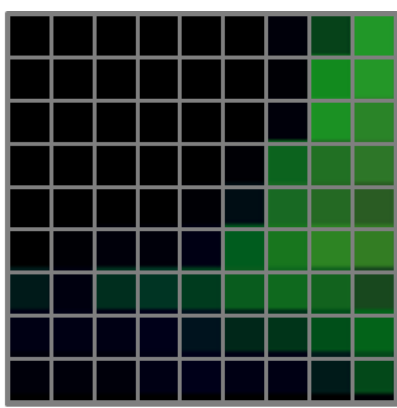

$100 \mathrm{~m}$

Fonte: Dutra et al. (2019).

\section{IMAGENS FRAÇÃO}

As imagens fração são os produtos gerados a partir da aplicação dos algoritmos matemáticos descritos anteriormente. Elas são representadas por imagens nas quais o valor do pixel corresponde às proporções dos componentes considerados na mistura espectral. Em geral, todos os algoritmos produzem o mesmo resultado, ou seja, geram as mesmas imagens frações quando as equações de restrição não são usadas, ou seja, as proporções estão no intervalo de 0 a 1 . Normalmente, as imagens fração de vegetação, solo e sombra/água são geradas, que são os componentes geralmente presentes em qualquer cena da superfície terrestre. As imagens fração podem ser consideradas como uma forma de redução da dimensionalidade dos dados e também uma forma de realce das informações. Além disso, o modelo de mistura espectral transforma as informações espectrais em informações físicas (valores de proporção dos componentes no pixel).

A imagem fração vegetação destaca as áreas de cobertura vegetal, a imagem fração solo destaca as áreas de solo exposto e a imagem fração sombra/água destaca as áreas ocupadas com corpos d'água, como rios e lagos, e também as áreas queimadas, as áreas úmidas, etc. A sombra e a água são consideradas juntas porque esses dois alvos exibem respostas semelhantes nas bandas espectrais normalmente usadas pelos sensores de observação da Terra, como por exemplo a baixa resposta espectral na região do espectro. Dessa forma, é importante ter em mente que o modelo de mistura espectral não é um classificador, mas uma técnica de transformação de imagem para facilitar a extração de informações (SHIMABUKURO; PONZONI, 2017).

A Figura 3 mostra um exemplo das respostas espectrais dos componentes da vegetação, solo e sombra/água utilizadas para gerar imagens fração em uma cena de órbita 231 e ponto 062 da imagem proveniente do sensor OLI (Operational Land Imager) a bordo do satélite Landsat-8, correspondente à região de Manaus (AM). Nesse caso, foram utilizadas, como exemplo, as imagens de todas as bandas: $1(0,43 \mu \mathrm{m}-$ 0,45 $\mu \mathrm{m}), 2(0,45 \mu \mathrm{m}-0,51 \mu \mathrm{m}), 3(0,52 \mu \mathrm{m}-0,60 \mu \mathrm{m}), 4(0,63 \mu \mathrm{m}-0,68 \mu \mathrm{m}), 5(0,84 \mu \mathrm{m}-0,88 \mu \mathrm{m}), 6$ $(1,56 \mu \mathrm{m}-1,66 \mu \mathrm{m})$ and $7(2,10 \mu \mathrm{m}-2,30 \mu \mathrm{m})$, que foram previamente convertidos em valores de reflectância de superfície. Vale lembrar que essa análise pode ser realizada usando esses valores de reflectância aparente ou de superfície ou mesmo NDs desde que o espectro dos componentes seja obtido a partir dessas imagens. A Figura 4A mostra uma composição colorida (R6 G5 B4) com base nas imagens do sensor OLI/Landsat-8, enquanto as figuras $5 \mathrm{~B}$ a $5 \mathrm{G}$ apresentam as imagens correspondentes as bandas espectrais 2 a 7.

Obviamente, o usuário deve levar em consideração o tipo de dados com o qual está trabalhando, 
principalmente na seleção de endmembers. O usuário com maior familiaridade com a análise de curvas de reflectância de diferentes recursos naturais provavelmente se sentirá mais confortável em selecionar endmembers ao trabalhar com imagens convertidas em valores de reflectância de superfície, pois o formato das curvas informará sobre a natureza dos pixels selecionados como puros. Isso não significa que eles não são capazes de fazer uma boa seleção trabalhando com imagens compostas de NDs. Nesse caso, o formato das curvas não seria muito útil, mas não interferiria no desempenho do modelo de mistura.

Figura 3 - Exemplo de resposta espectral dos componentes da vegetação, solo e sombra/água.

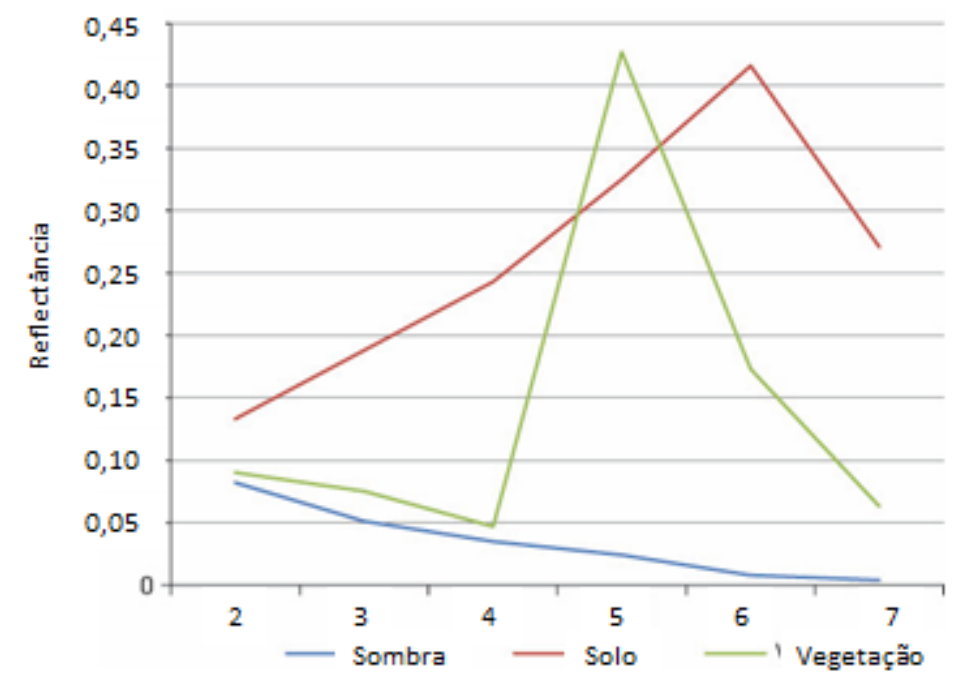

Fonte: Shimabukuro e Ponzoni (2017).

Figura 4 - (A) composição colorida (R6 G5 B4) de OLI/Landsat-8 para a imagem de órbita 231 e ponto 062; (B) banda 2; (C) banda 3; (D) banda 4; (E) banda 5; (F) banda 6; (G) banda 7.

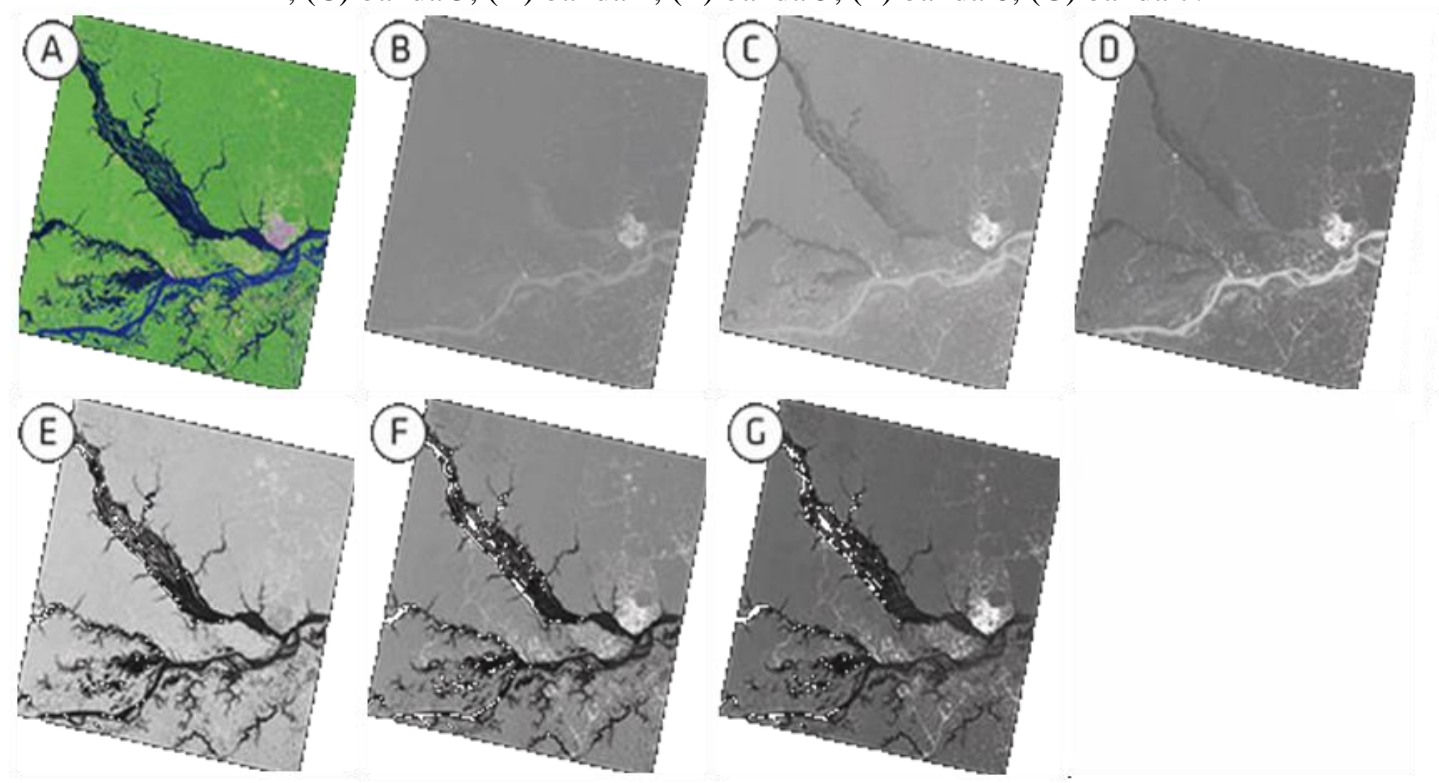

Fonte: Shimabukuro e Ponzoni (2017).

Como resultado, utilizando as imagens acima provenientes do sensor OLI/Landsat-8, observa-se que na imagem fração solo (Figura 5B), os pixels mais brilhantes são aqueles que têm os níveis mais baixos de cobertura vegetal ou menos sombreados. Enquanto a imagem fração vegetação apresentada na Figura 5C mostra que os pixels mais brilhantes são aqueles que têm maior quantidade de vegetação, enquanto os corpos d'água aparecem escuros, pois não possuem porcentagem de cobertura vegetal. Uma análise semelhante pode ser feita com as imagens de outros componentes. 
Figura 5 - (A) mostra a composição colorida das imagens fração (Rsolo Gvegetação Bsombra/água) derivadas do sensor OLI/ Landsat-8 para a região de Manaus (AM). As imagens fração correspondentes são: (B) solo, (C) vegetação e (D)
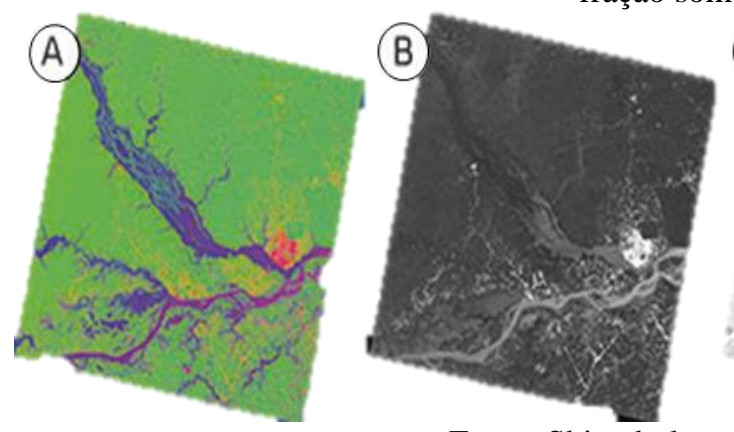
fração sombra/água.

Fonte: Shimabukuro e Ponzoni (2017).
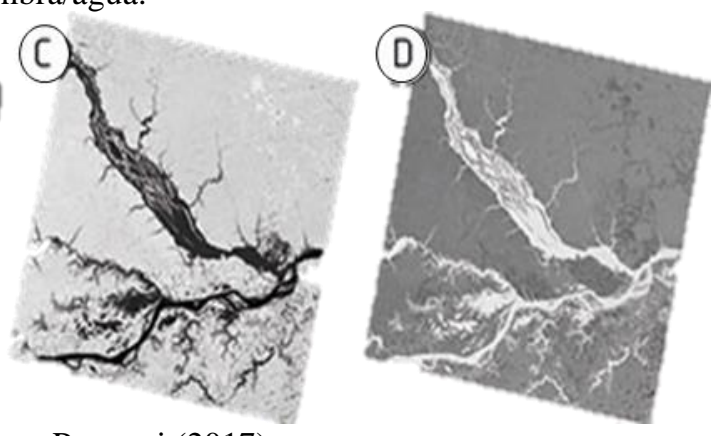

Observa-se que as imagens frações são monocromáticas (escala de cinza), e os valores pixel a pixel em cada imagem estão diretamente associados às proporções (abundância) de cada um dos respectivos componentes da cena selecionada para o modelo de mistura espectral. Assim, quanto maior o valor de um pixel em uma imagem fração vegetação (Figura 6B), por exemplo, maior a proporção de vegetação no pixel correspondente (verde brilhante na Figura 6A). A mesma interpretação se aplica às imagens de outros componentes: quanto maior o valor em uma imagem fração solo (Figura 6C), maior a proporção de solo no pixel correspondente (magenta na Figura 6A) e quanto maior o valor em uma imagem fração sombra/água (Figura 6D), maior a proporção de água ou queimada no pixel correspondente (magenta escuro ou preto na Figura 6A).

Figura 6 - (A) composição colorida (R6 G5 B4) do OLI/Landsat-8 da parte da imagem orbita 226/ponto 068 no estado de Mato Grosso, e imagens fração (B) vegetação, (C) solo e (D) sombra/água.

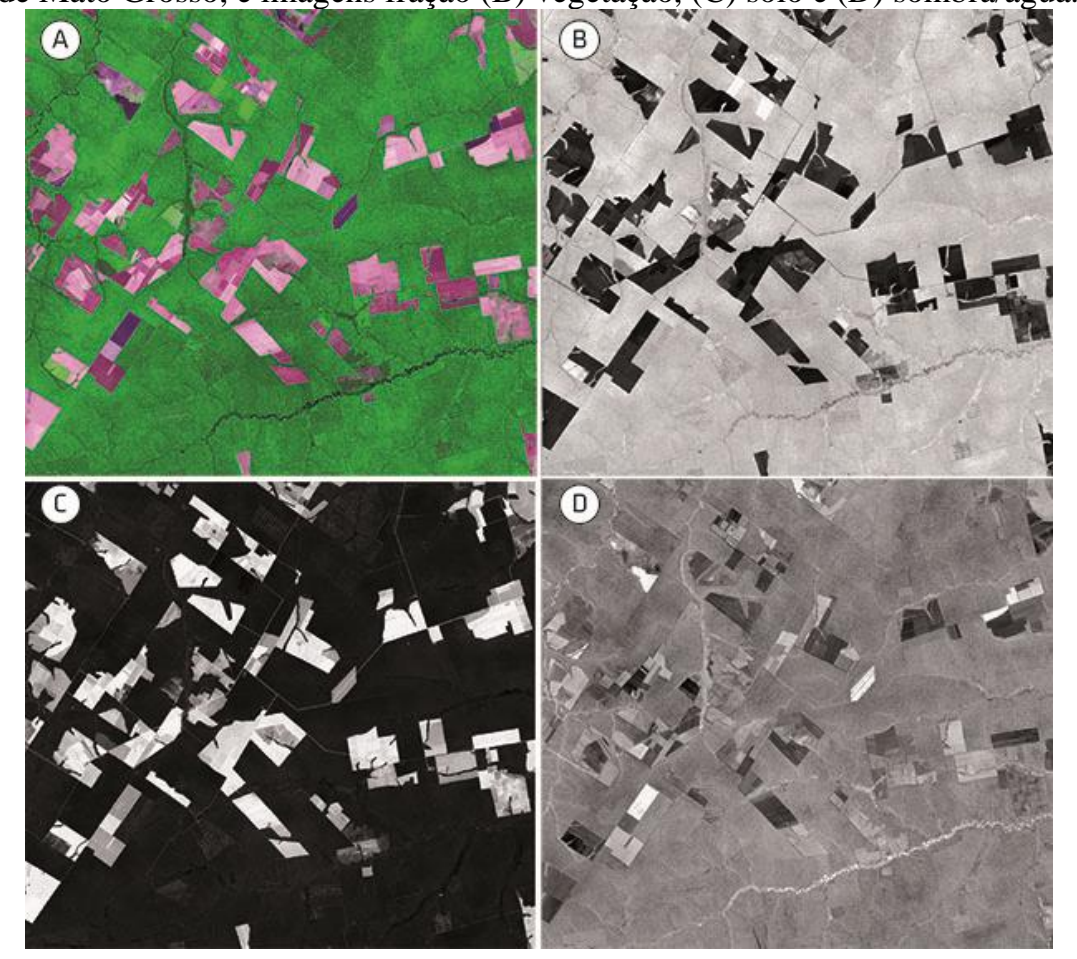

Fonte: Shimabukuro e Ponzoni (2017).

A escala de cinza das imagens fração é mais clara com a maior proporção de endmembers no pixel. A mesma convenção é adotada para a imagem de erro associada ao modelo. A escolha da convenção é arbitrária, de modo que, às vezes, os tons da imagem podem ser revertidos para ajudar na visualização dos padrões. Por exemplo, no caso da imagem da fração sombra/água, geralmente é mais intuitiva quando os tons são invertidos, de modo que os tons escuros indicam menos iluminação (ADAMS; GILLESPIE, 2006). As imagens fração também podem ser apresentadas em composição colorida (RGB) selecionando três imagens correspondentes 
aos endmembers. Nesse caso, o alongamento do contraste da imagem pode ser aplicado para a visualização dos padrões, mas distorce os valores da proporção para o uso quantitativo. Para analisar uma imagem fração individualmente, é mais eficaz apresentar as proporções mais altas dos endmembers em tons de cinza mais brilhantes, para destacar o alvo de interesse.

A literatura apresenta uma grande quantidade de trabalhos sobre o uso do modelo linear de mistura espectral em várias regiões do mundo, mostrando que essa técnica é consistente. Além disso, as imagens fração geradas por este modelo estão sendo usadas em diferentes áreas de aplicação, como florestas (SHIMABUKURO, 1987), agricultura (WHITE et al., 2002; YANG et al., 2007), uso e cobertura da terra (SHIMABUKURO et al., 2020), água (NOVO; SHIMABUKURO, 1994; ALCÂNTARA et al., 2009) e áreas urbanas (WU; MURRAY, 2003).

Como pode ser visto, a proporção de cada endmember pode ser mostrada para cada pixel, criando uma imagem útil para a fotointerpretação. As imagens fração são derivadas com base nas informações de todas as bandas multiespectrais usadas. Dessa forma, para cada tipo de aplicação, pode ser limitado o número de bandas a serem empregadas, por exemplo, a análise de áreas desmatadas na Amazônia apenas três bandas são suficientes: vermelho, infravermelho próximo e infravermelho médio pois são faixas espectrais pouco correlacionadas e correspondem as bandas convencionalmente utilizadas por diversos autores (SKOLE; TUCKER, 1993; SHIMABUKURO et al., 1998; INPE, 2008).

Portanto, a conversão dos dados espectrais em imagens fração por meio do modelo linear de mistura espectral pode resultar em uma redução significativa na dimensionalidade dos dados a serem analisados. Por exemplo, é possível usar várias bandas dos sensores - seis bandas do TM, sete bandas do MODIS, 242 bandas do Hyperion para gerar um pequeno número de imagens fração (geralmente, três ou quatro endmembers).

Agora, uma vez conhecidas as proporções das imagens frações e as respostas espectrais dos endmembers, é possível recuperar as respostas espectrais dos pixels em cada uma das bandas espectrais utilizadas (SHIMABUKURO; SMITH, 1995; DUTRA et al., 2019). Este procedimento permite avaliar o desempenho dos modelos na geração de imagens fração pela formação das imagens de erro.

Assim, com base no modelo de mistura espectral, é possível calcular o erro para cada uma das bandas espectrais e gerar as imagens de erro correspondentes, uma vez que a resposta dos componentes e suas proporções são conhecidas. Essa é uma maneira de avaliar o desempenho do modelo, ou seja, quando o modelo é apropriado, as imagens de erro mostram um aspecto sem nenhum padrão. Se houver um componente que não tenha sido considerado na mistura, ele será destacado nas imagens de erro das bandas espectrais empregadas. As imagens de erro geralmente apresentam valores baixos de acordo com a precisão dos modelos empregados. Dessa forma, essas imagens são usadas para avaliar a qualidade dos modelos definidos, ou seja, se o número de componentes foi adequado para a cena analisada.

\section{APLICAÇÕES NA REGIÃO AMAZÔNICA}

A seguir serão apresentados alguns exemplos do uso das imagens fração derivadas do modelo linear de mistura espectral em projetos de monitoramento ambiental na Amazonia Legal (AML) (Figura 7). As imagens fração contribuíram para o desenvolvimento de pesquisas em pequena escala, como também em projetos de grande escala que utilizam uma grande quantidade de imagens. 
Figura 7 - Localização da Amazônia Legal Brasileira na América do Sul e seus respectivos estados. (A) Composição colorida (Rmir Gnir Bred) provenientes das imagens VIIRS-NPP para a Amazônia Legal, (B) e a respectiva composição

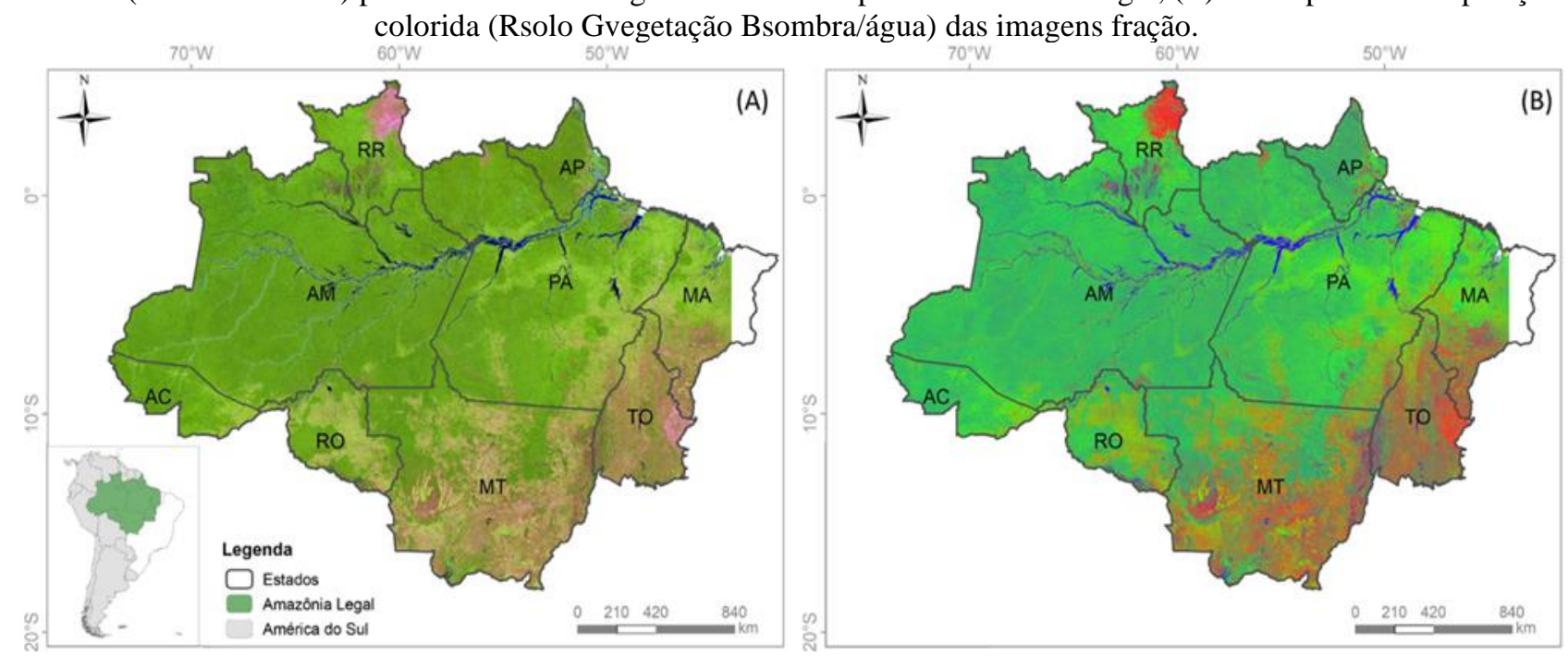

Fonte: Os autores (2020).

\subsection{Mapeamento do Uso e Cobertura da Terra}

As imagens fração de vegetação, solo e fração sombra/água foram usadas para mapear o uso e cobertura da terra em escala nacional (SHIMABUKURO et al., 2020; ARAI et al., 2020) e em escala regional (CASSOL et al., 2020). A Figura 8 representa a ideia conceitual utilizada no mapeamento da agricultura no estado do Mato Grosso usando dados multitemporais do satélite PROBA-V aplicando a metodologia de máxima proporção das imagens fração obtidas na série temporal de um ano (ARAI et al., 2020). Nesse exemplo, considerando a série temporal de, aproximadamente, 288 imagens (72 cenas x quatro bandas espectrais) provenientes do satélite utilizado no estudo, a aplicação do MLME permitiu a identificação das áreas destinadas à agricultura devido à sua caracterização por áreas homogêneas e por um padrão cíclico entre solo exposto (colheita e preparo do solo) e vegetação. Nesse tipo de uso da terra, diferentemente de outros tipos de uso e cobertura, o pixel apresenta alta proporção da fração solo em determinado período do ano e alta proporção da fração vegetação quando o cultivar atinge o pico vegetativo, razão pela qual foi adotada a máxima proporção das frações. Além disso, foi possível reduzir o volume de dados para três imagens, representadas por imagens fração, considerando as informações de toda a série temporal para, então, realizar as etapas de classificação da imagem.

Figura 8 - (A) composição conceitual de um pixel com diferentes elementos dentro de um pixel; (B) a resposta espectral teórica subsequente de seus elementos para obter os endmembers; e (C) representação teórica do comportamento temporal das imagens fração da vegetação e a variação das proporções ao longo do período de estudo.

(A) Pixel do Proba-V

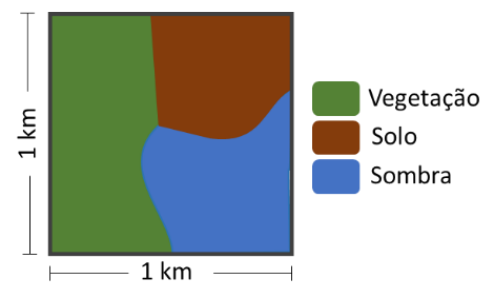

(B) Resposta espectral teórica

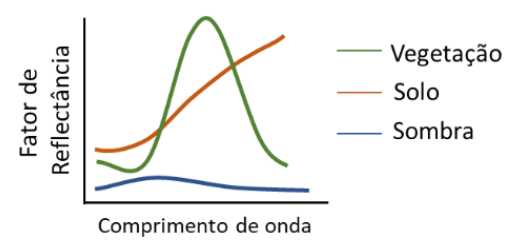

(C) Série temporal teórica de imagens fração vegetação

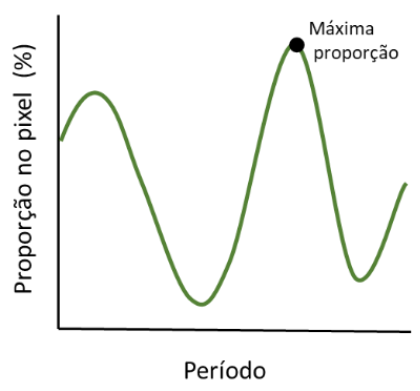

Fonte: Arai et al. (2020). 
A Figura 9 apresenta um exemplo das imagens fração máxima de vegetação, solo e sombra no estado do Mato Grosso derivadas das imagens PROBA-V adquiridas no ano de 2015. Na imagem fração vegetação (Figura 9A), é possível observar as áreas agrícolas em destaque, principalmente soja. Por outro lado, na imagem fração solo (Figura 9B), é possível observar o contraste entre as áreas sem ou pouca vegetação (áreas desmatadas e áreas de cerrado cuja vegetação é mais espacialmente heterogênea, em claro) e com vegetação densa (cobertura florestal, em escuro). Na imagem fração sombra/água, podemos observar as áreas de corpos d’água e áreas queimadas.

Figura 9 - Imagens frações máxima de vegetação (A), de solo (B) e de sombra (C) derivadas das imagens PROBA-V do estado de Mato Grosso adquiridas em 2015.
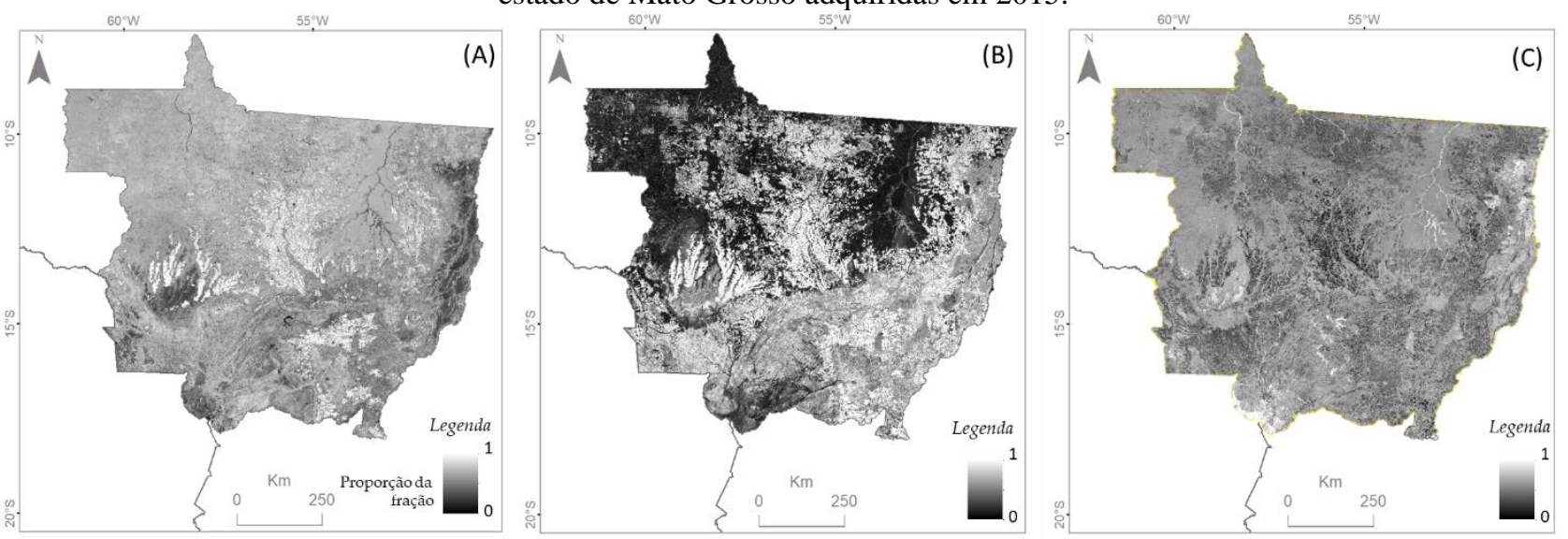

Fonte: Shimabukuro et al. (2020).

Como outro exemplo para o mapeamento do uso e cobertura da terra utilizando as imagens fração, na Figura 10 é exibido o resultado do mapeamento no estado do Mato Grosso em 2015 utilizando a abordagem de máxima fração para separar as classes de uso e cobertura da terra, incluindo pastagem e áreas de savana que apresentam maior dificuldade de distinção por classificação automática. Os autores realizaram a discriminação das classes com base nas variações nas proporções das imagens fração de solo, vegetação e sombra, de acordo com a sazonalidade, ao invés de analisar seus comportamentos espectrais, que invariavelmente mudam com o sensor e a resolução espacial. Isso significa que cada classe tem um comportamento anual típico de acordo com seu aumento ou diminuição nas proporções de vegetação, solo e sombra ao longo da série temporal de um ano (CASSOL et al., 2020).

Figura 10 - Mapa de uso e cobertura da terra no estado do Mato Grosso, obtido com base na série temporal anual de imagens do PROBA-V de 2015.

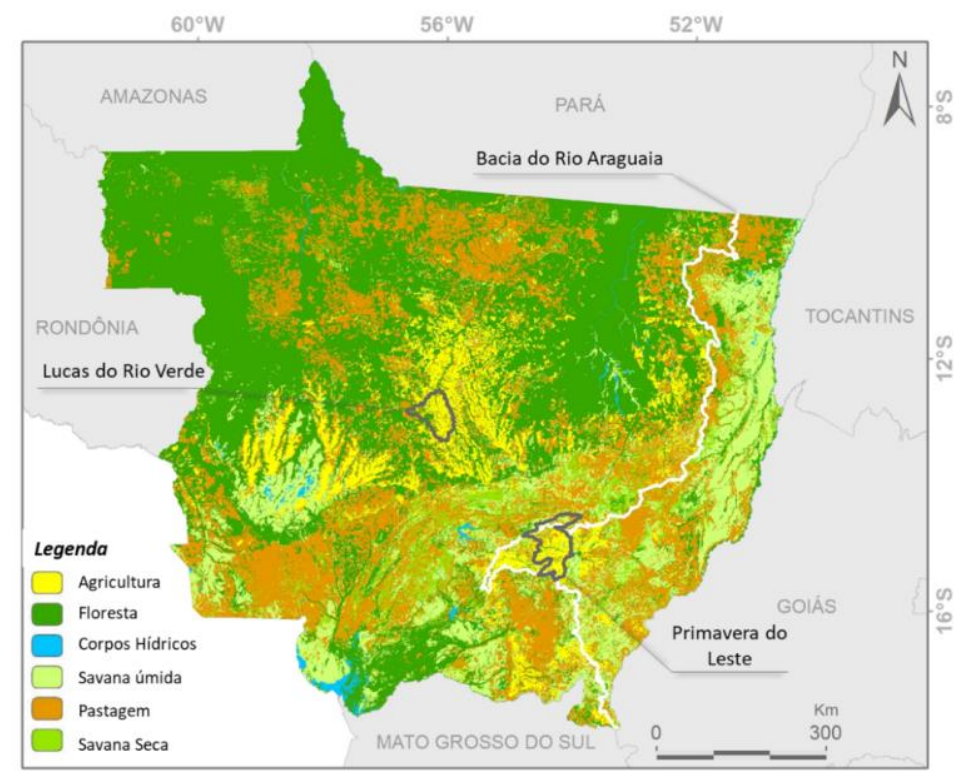

Fonte: Cassol et al. (2020). 
Como mencionado, os componentes vegetação, solo, e sombra/água são comumente utilizados nas aplicações com os modelos lineares de mistura pois geralmente estão presentes em qualquer cena da superfície terrestre. Esses componentes, integrados, podem fornecer informações importantes no mapeamento e monitoramento dos diferentes tipos de uso e cobertura da terra pois estão relacionados à dinâmica dos alvos na superfície e como eles se comportam ao longo do tempo, facilitando a discriminação dos diferentes alvos. A Figura 11 representa, de modo conceitual e ilustrativo, a dinâmica desses três componentes em diferentes coberturas da terra. Em geral, pixels que contêm vegetação densa ou espacialmente homogênea, como agricultura e floresta, apresentam proporções médias a altas de vegetação e proporções baixas de solo. Por outro lado, vegetações menos densas ou mais esparsas, como vegetação degradada, herbácea ou campestre, apresentam proporções intermediárias de vegetação e solo devido à mistura de ambos os componentes no pixel. Corpos d'água, como rios e lagos perenes, apresentam elevada proporção de sombra e proporções quase nulas de vegetação e solo. Áreas com solo exposto apresentam elevada proporção de solo e proporções quase nulas de vegetação, o que permite identificar, por exemplo, áreas desmatadas ou degradadas por corte seletivo de madeira (pátios e carreadores). Fatores como sombra das árvores, nuvens e sombra de nuvens também influenciarão na proporção da fração sombra, assim como áreas queimadas, devido à sua baixa reflectância na região do visível.

Ao analisar o comportamento dos três componentes ao longo do tempo, observam-se as variações das proporções dos alvos na superfície terrestre resultante da dinâmica da sazonalidade e outros fatores como, por exemplo, nuvens. Em áreas agrícolas, por exemplo, são observadas variações nas proporções de solo e vegetação durante a estação de crescimento, as fases de colheita e pré-semeadura. Assim como também são observadas variações em vegetações mais sazonais, característica observada no cerrado, por exemplo. Além disso, rios e lagos intermitentes apresentam variação da proporção sombra e solo. Com isso, as imagens fração podem ser aplicadas para diversos objetivos e o conhecimento da dinâmica no espaço e tempo entre os componentes pode subsidiar pesquisas futuras neste campo do conhecimento.

Figura 11 - Exemplificação conceitual da proporção dos principais componentes da superfície terrestre (vegetação, solo

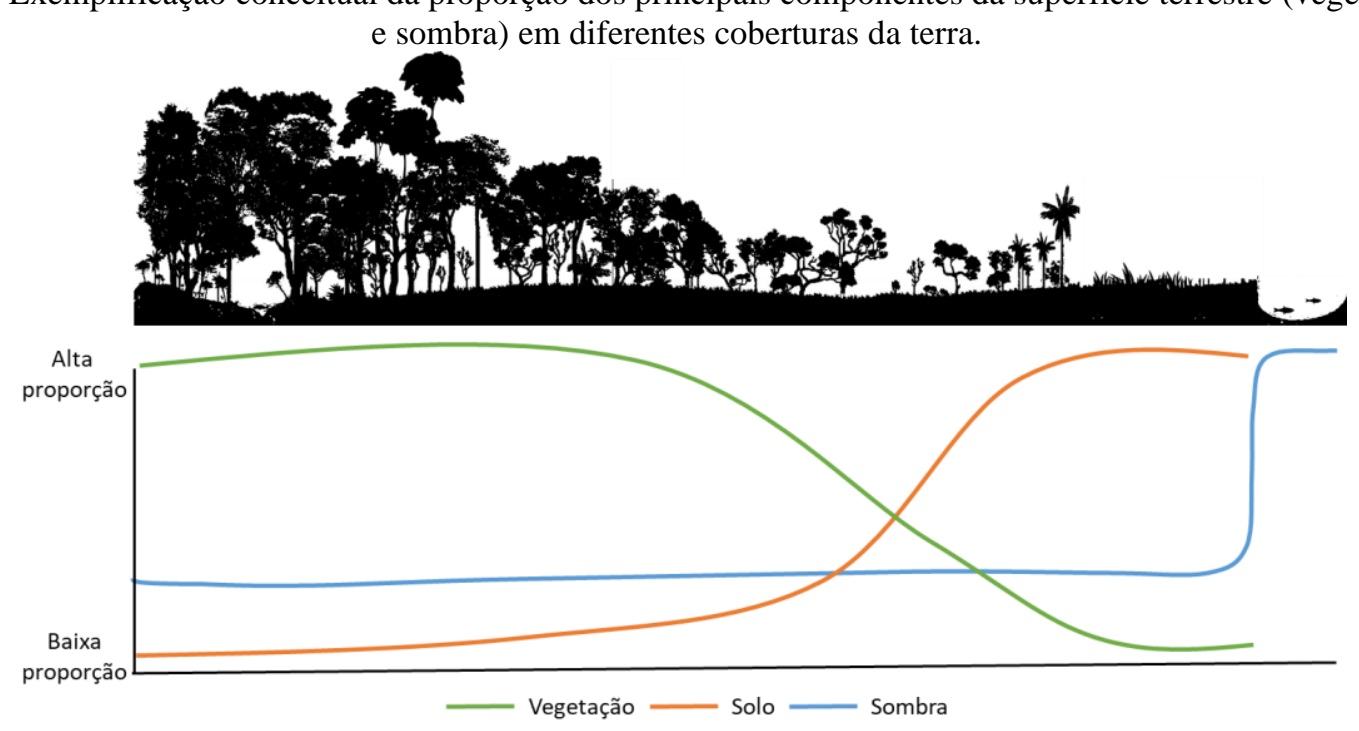

Fonte: Os autores (2020).

\subsection{Mapeamento de desmatamento}

O desmatamento na Amazônia Legal tem sido motivo de preocupação de várias organizações governamentais e não-governamentais, especialmente nas últimas três décadas (MORAN, 1981; SKOLE; TUCKER, 1993). Embora não exista uma longa história de ocupação humana na AML, quase 90\% do desmatamento para pastagens e agricultura ocorreu entre o período de 1970 a 1988, conforme indicado pelas estimativas baseadas em imagens de satélite (SKOLE et al., 1994).

Historicamente, o território brasileiro era ocupado ao longo da costa, com a maioria de sua população 
concentrada nessa região. Na tentativa de mudar esse padrão de ocupação, aumentando a ocupação no interior do país, a capital federal foi transferida do litoral, no Rio de Janeiro, para a região central, em Brasília, em meados de 1950 (MAHAR, 1988). Essa política de ocupação exigia investimentos em infraestrutura para conectar Brasília às demais regiões do país. A construção da rodovia Belém-Brasília (BR-010), em 1958, foi o fator dominante que desencadeou as principais atividades de desmatamento na AML (MORAN et al., 1994; NEPSTAD et al., 1997). Eventos subsequentes, como a construção da BR-364, atravessando os Estados de Mato Grosso, Rondônia e Acre, e a PA-150, no Estado do Pará, incentivaram outras atividades de desmatamento, convertendo florestas em áreas de pastagem e agricultura (MORAN, 1993).

Para introduzir a governança na AML, a "Superintendência de Desenvolvimento da Amazônia" (SUDAM) e o "Banco da Amazônia" (BASA) foram fundados em 1966. Pequenos produtores foram financiados para incentivar o investimento em projetos de agricultura (MORAN et al., 1994). Grandes produtores também foram financiados através de incentivos fiscais no comércio para converter florestas em áreas de pastagem (MORAN, 1993). Os incentivos concedidos aos grandes produtores foram as principais causas do desmatamento; os pequenos produtores tiveram um impacto menor no desmatamento devido à prática de dimensão comparativamente menor da agricultura de subsistência (FEARNSIDE, 1993).

Outras atividades de alto valor econômico, como mineração e exploração seletiva de madeira, também contribuíram para o desmatamento na AML (COCHRANE et al., 1999). As áreas de desmatamento na Amazônia Legal brasileira estão concentradas no chamado arco de desmatamento, localizado nas partes sul e leste da AML, do Acre aos estados do Maranhão (COCHRANE et al., 1999; ACHARD et al., 2002 )

Desde 1973, o Brasil tem acesso às imagens de sensoriamento remoto dos satélites Landsat, que permitem quantificar a extensão dos recursos naturais e a mudança da região amazônica. Com base na disponibilidade dessas imagens, o governo brasileiro começou a monitorar a floresta amazônica para quantificar as áreas de desmatamento em intervalos de vários anos.

O governo brasileiro realiza monitoramento sistemático anual da floresta amazônica desde 1988, utilizando imagens geradas pelo programa Landsat por meio do projeto PRODES (Monitoramento da floresta amazônica brasileira por satélite), realizado pelo INPE. Sendo o maior projeto de sensoriamento remoto do mundo para monitorar a atividade de desmatamento em florestas tropicais, o PRODES tem como objetivo avaliar todas as áreas desmatadas dentro dos 5 milhões de quilômetros quadrados da Amazônia Legal Brasileira.

Este projeto estimou aproximadamente $810.000 \mathrm{~km}^{2}$ de desmatamento na Amazônia brasileira até o ano de 2019 (INPE, 2020; ASSIS et al., 2019), total que representa aproximadamente $18 \%$ da extensão florestal original. Esses dados mostram taxas anuais de desmatamento que variam significativamente em resposta às condições políticas, econômicas e financeiras do país, bem como às demandas do mercado externo.

As informações do PRODES baseiam-se principalmente em imagens de sensores com resolução espacial média (30 m), como as geradas pelo programa Landsat, e com resolução temporal relativamente baixa (frequência de aquisição de 16 dias), permitindo o monitoramento anual do desmatamento. Uma atualização mais rápida da mudança de floresta não é possível com essas imagens devido à baixa frequência de aquisição de imagens sem nuvens, o que é um problema sério para a região amazônica, limitando o número de observações viáveis da superfície do solo. Esse fato impede que o governo e as agências de controle ambiental façam intervenções rápidas e apropriadas para interromper as atividades de desmatamento ilegal.

Desse modo, para monitorar o desmatamento em tempo quase real, foram utilizadas as imagens quase diárias do sensor MODIS nas plataformas Terra e Aqua. Assim, por meio do projeto DETER (Detecção de desmatamento quase em tempo real), uma nova metodologia baseada em imagens MODIS foi desenvolvida para a detecção rápida de desmatamento na Amazônia (ANDERSON et al., 2005; SHIMABUKURO et al., 2006). Embora o MODIS seja um sensor de resolução espacial moderada e não gere imagens viáveis para estimar a extensão do desmatamento, os dados do MODIS são valiosos como indicadores de mudanças ou como produto de alarme para o serviço de gerenciamento e controle de políticas da superfície do solo. Atualmente, os projetos contam com sensores de maior resolução espacial, a bordo dos satélites Sentinel, Landsat e CBERS. 


\subsubsection{PROJETO PRODES DIGITAL}

Desde o final de 1970, o INPE realiza avaliações do desmatamento na AML usando imagens de sensoriamento remoto. Essas avaliações foram feitas em conjunto com o antigo Instituto Brasileiro de Desenvolvimento Florestal (IBDF), que mais tarde foi incorporado ao Instituto Brasileiro de Meio Ambiente e Recursos Naturais Renováveis (IBAMA). A primeira avaliação foi realizada com o uso de imagens adquiridas pelo sensor MSS, com quatro bandas espectrais e resolução espacial de $80 \mathrm{~m}$, a bordo dos satélites Landsat 1, 2 e 3, durante os períodos de 1973 a 1975 e 1975 a 1978, empregando interpretação visual de imagens (TARDIN et al., 1980).

A partir de 1988, as avaliações anuais de desmatamento foram fornecidas a toda a AML usando o sensor TM, seis bandas espectrais com resolução espacial de $30 \mathrm{~m}$, a bordo do satélite Landsat 5, com melhor qualidade de mapeamento devido a suas melhores resoluções espaciais e espectrais quando comparado com os dados do MSS. A metodologia aplicada ao mapeamento de áreas desmatadas era baseada na interpretação visual de composições coloridas (R5 G4 B3) de imagens TM em formato impresso, em uma escala de 1: 250.000. Os polígonos interpretados visualmente das áreas desmatadas eram somados para calcular o total de áreas desmatadas para cada estado da AML e apresentados em forma de tabelas. Esse método, conhecido como PRODES analógico, foi realizado até 2003.

No final da década de 1990, começou a ser desenvolvida uma metodologia semi-automatizada utilizando as imagens fração, denominada PRODES Digital (SHIMABUKURO et al., 1998). O projeto PRODES Digital é uma automação das atividades desenvolvidas no projeto PRODES. Para que o PRODES detecte desmatamento na AML brasileira, uma máscara de floresta intacta é atualizada anualmente através da identificação de um novo evento de desmatamento para excluir as áreas de vegetação não florestal e a identificação de outras mudanças dinâmicas, como as áreas de regeneração secundária. As imagens provenientes dos satélites utilizados são selecionadas para o período de julho, agosto e setembro, que é no período da estação seca no arco do desmatamento e representa uma janela atmosférica quando as imagens sem nuvens normalmente estão disponíveis. As bandas nas faixas espectrais do vermelho, infravermelho próximo e infravermelho médio são usadas para gerar as imagens frações (SHIMABUKURO et al., 1998).

O PRODES digital consiste nas seguintes etapas metodológicas (Figura 12): (1) geração de imagens fração de vegetação, solo e sombra/água; (2) segmentação de imagens com base no algoritmo de crescimento de regiões; (3) classificação de imagens com base em classificador não supervisionado; (4) classes de mapeamento com base na seguinte legenda: floresta, não floresta (vegetação que não é caracterizada por uma estrutura florestal), desmatamento (desmatamento acumulado até o ano anterior), hidrografia, desmatamento anual, e nuvens; e (5) edição do mapa classificado com base na interpretação visual para minimizar erros de omissão e comissão da classificação automática, a fim de produzir o mapa final do desmatamento em formato digital.

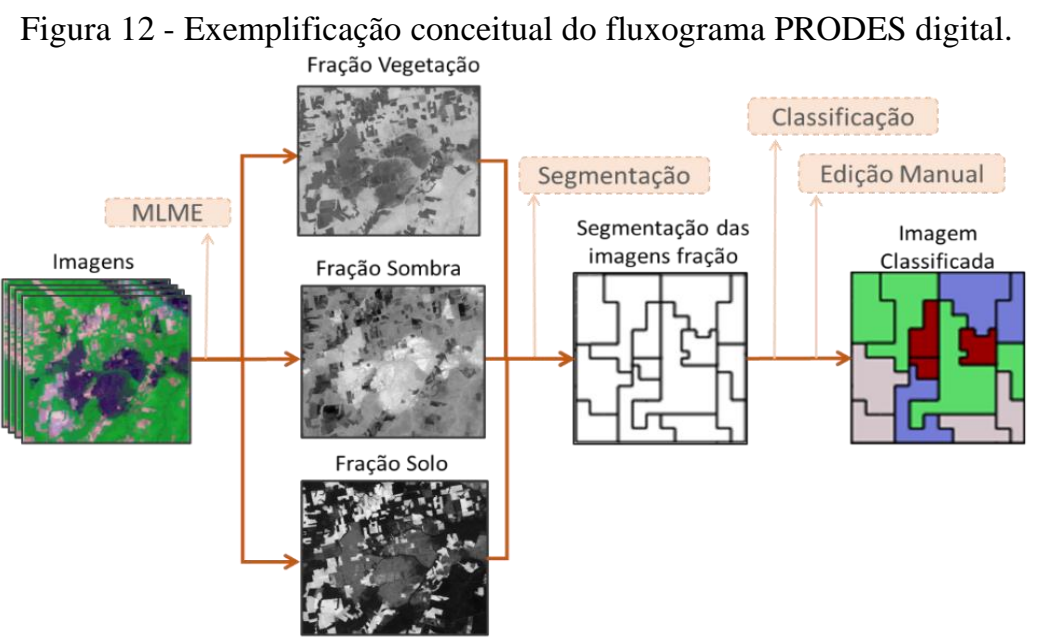

Fonte: Os autores (2020). 
A imagem fração sombra/água foi utilizada para caracterizar a área total desmatada antes de 1997 na AML, de acordo com a metodologia proposta por Shimabukuro et al. (1998). Nesse caso, a imagem fração sombra/água foi utilizada por homogeinizar as áreas de floresta (média quantidade de sombra) distinguindo das outras classes de uso da terra (baixa quantidade de sombra) como as áreas de solo exposto, pastagem e áreas de regeneração. Posteriormente, as áreas desmatadas foram acumuladas até o ano 2000. Para o mapeamento de desmatamento anual, a imagem fração solo é utilizada pois destaca as áreas sem cobertura vegetal, que correspondem ao incremento anual do desmatamento com base no alto contraste entre as áreas florestadas e desmatadas. As imagens fração sombra e vegetação também podem ser usadas para o mapeamento de desmatamento anual, uma vez que as áreas de floresta e não floresta (floresta recém cortada) são muito distintas nessas imagens. Mas a imagem fração solo destaca melhor as áreas recém desmatadas. $\mathrm{O}$ PRODES Digital permitiu ao INPE colocar à disposição da comunidade em geral as informações das áreas desmatadas na AML (Figura 13), sendo reconhecido nacionalmente e internacionalmente (KINTISCH, 2007).

Figura 13 - Mapa de desmatamento na Amazônia Legal Brasileira.

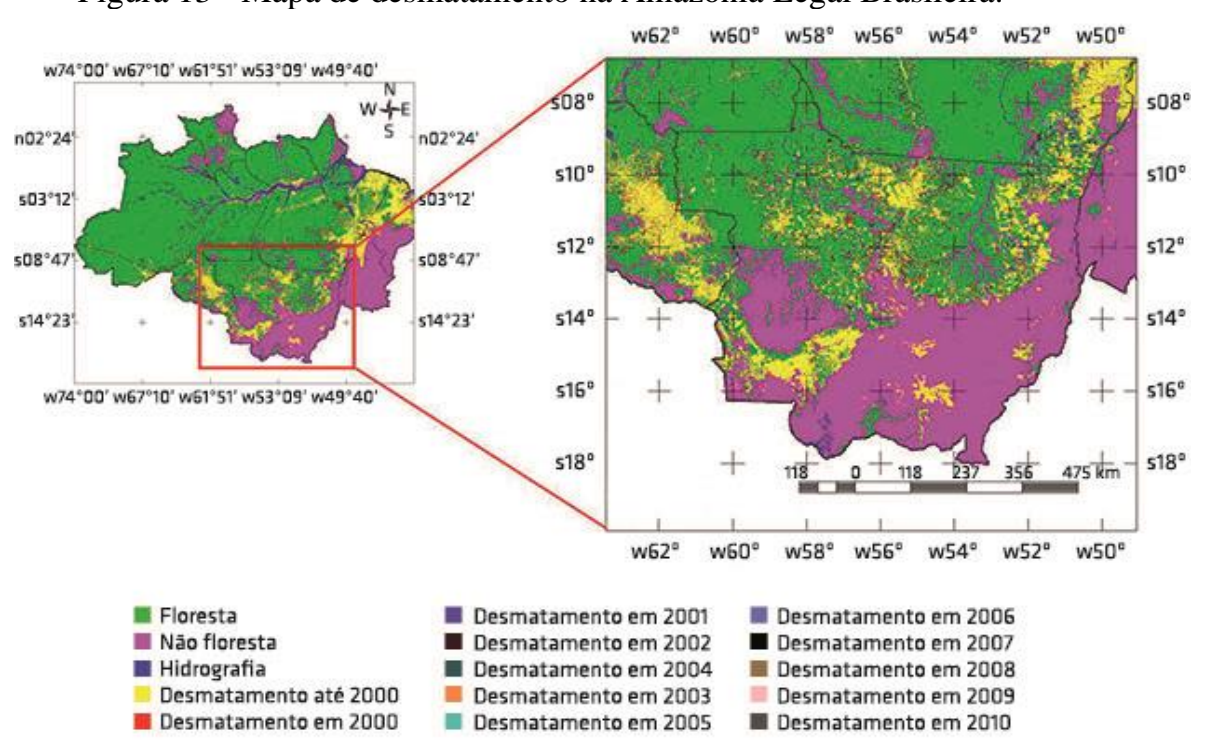

Fonte: Shimabukuro e Ponzoni (2017).

\subsubsection{PROJETO DETER}

Desde 2004, o projeto DETER foi implementado com o objetivo de fornecer detecção em tempo quase real das atividades de desmatamento para apoiar o plano de ação do Governo Federal para a prevenção e controle do desmatamento na AML brasileira. O procedimento utiliza a metodologia adotada no projeto PRODES Digital, mas tem como objetivo detectar atividades de desmatamento em tempo real, explorando a resolução temporal do sensores MODIS (ANDERSON et al., 2005; SHIMABUKURO et al., 2006).

O primeiro passo no método do projeto DETER é "mascarar" a floresta intacta com base nos resultados do PRODES no ano anterior. O mapa da floresta intacta é usado como referência para identificar novos eventos de desmatamento em tempo real ao longo do ano analisado. A atividade de monitoramento com as imagens começa em janeiro, mas se torna mais efetiva após março, quando um número maior de imagens está disponível devido à menor cobertura de nuvens na AML.

No DETER, as imagens diárias MODIS (reflectância da superfície MOD09) eram selecionadas com base em dois critérios: (a) quantidade de cobertura de nuvens e (b) faixa dentro do ângulo zenital do sensor menor que $35^{\circ}(\sim 1.400 \mathrm{~km})$. A quantidade de nuvens é avaliada inicialmente de acordo com as imagens de visualização rápida, seguidas de análises mais detalhadas com a resolução espacial real das imagens MODIS utilizadas. A AML é coberta por 12 tiles MODIS (V09 a V11 e H10 a H13).

Do conjunto de sete bandas do produto MOD09, as bandas 1 (vermelha), 2 (NIR) e 6 (MIR) são utilizadas para gerar imagens fração de vegetação, solo e sombra/água, aplicando o modelo linear de mistura espectral. As imagens fração solo são então segmentadas, classificadas, mapeadas e eventualmente editadas 
pelo intérprete, seguindo os mesmos métodos usados no projeto PRODES Digital. As áreas desmatadas classificadas nas imagens da fração do solo (Figura 14A e 14B) são sobrepostas à máscara da floresta, destacando as áreas de novos desmatamentos (cor vermelha na Figura 14C). Este procedimento é realizado para cada imagem diária adquirida para a AML brasileira. Os resultados das atividades de desmatamento detectados pelo DETER podem ser acumulados por diferentes intervalos, como semanais, quinzenais e mensais (Figura 14D).

Figura 14 - (A) imagem da fração solo (mosaico de 22 de abril a 7 de maio de 2004); (B) resultado da classificação da imagem da fração do solo; (C) classificação da imagem MODIS (mosaico de 22 de abril a 7 de maio de 2004) sobre a extensão total: agosto de 2003 + alteração até 7 de maio de 2004; e (D) resultado do monitoramento do projeto DETER, exibindo as atividades de desmatamento detectadas mensalmente durante o ano de 2004.
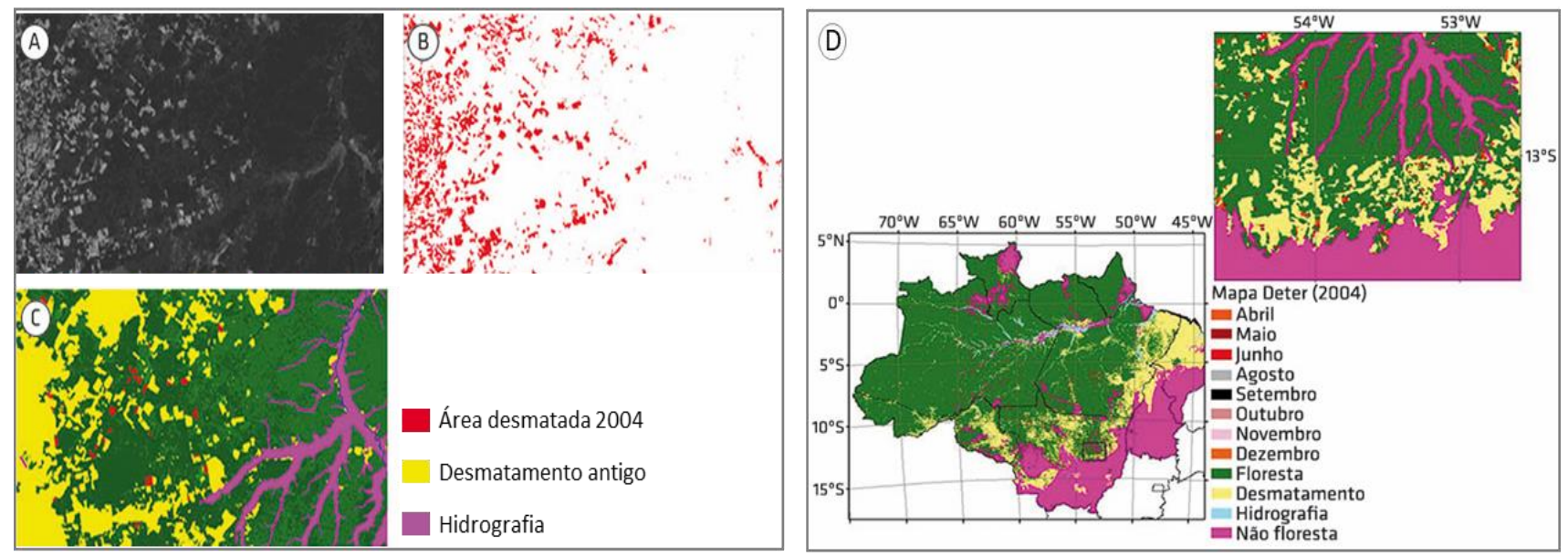

Fonte: Adaptado de Shimabukuro e Ponzoni (2017).

\subsection{Detecção de áreas de corte seletivo da madeira}

A extração seletiva de espécies de alto valor comercial é uma prática utilizada em áreas da floresta amazônica, exigindo vários estudos para sua detecção e mensuração, além da avaliação dos impactos em florestas intactas (ASNER et al., 2005; GROGAN et al., 2008; MATRICARDI et al., 2010; SHIMABUKURO et al., 2019).

A extração seletiva é caracterizada pela abertura de áreas de estocagem e trilhas ou estradas de exploração. Dessa forma, com o uso de imagens de média resolução espacial (proveniente dos satélites Landsat e Sentinel-2, por exemplo), é possível detectar essas áreas usando a imagem fração solo gerada pelo modelo linear de mistura espectral (SHIMABUKURO et al., 2019). A geração das imagens fração para este fim permitem realçar essas áreas de interesse que nem sempre são visualizadas facilmente em uma composição colorida (Figura 15A) por interpretação visual. A medida que a floresta se torna degradada com a retirada das árvores, as proporções das frações de solo aumentam devido à diminuição da cobertura do dossel e as proporções de vegetação diminuem, quando comparados as proporções dessas frações em florestas intactas. Com isso, o uso das imagens fração facilita e aumenta a detecção dos pátios de estocagem de madeira e estradas de exploração devido ao comportamento espectral dessas áreas, permitindo a melhor discriminação dessas áreas e facilitando o processo posterior de classificação. A Figura 15B mostra a imagem fração solo destacando as áreas caracterizadas por corte seletivo, apresentando os pátios para estocagem e trilhas para o carregamento das toras de madeira, que podem ser identificadas em campo conforme mostrado na Figura 15C-D.

Estabelecer um método operacional e eficiente para detectar e monitorar a degradação florestal por corte seletivo tem sido objeto de estudo na literatura e muitos esforços foram relatados utilizando imagens fração para mapear a extração seletiva (ASNER et al., 2005; ANWAR; STEIN, 2012) e o desenvolvimento de índices como o NDFI (Normalized Difference Fraction Image) utilizando imagens fração de vegetação (GV Green Vegetation), vegetação não fotossinteticamente ativa (NPV - Non-Photosynthetic Vegetation) e solo (SOUZA JR et al., 2005) para análise de degradação florestal. 
Figura 15 - (A) Composição colorida RGB e (B) imagem fração solo correspondente derivada de uma imagem Landsat OLI em uma área no estado de Mato Grosso, destacando as áreas de extração seletiva, caracterizadas pela presença de

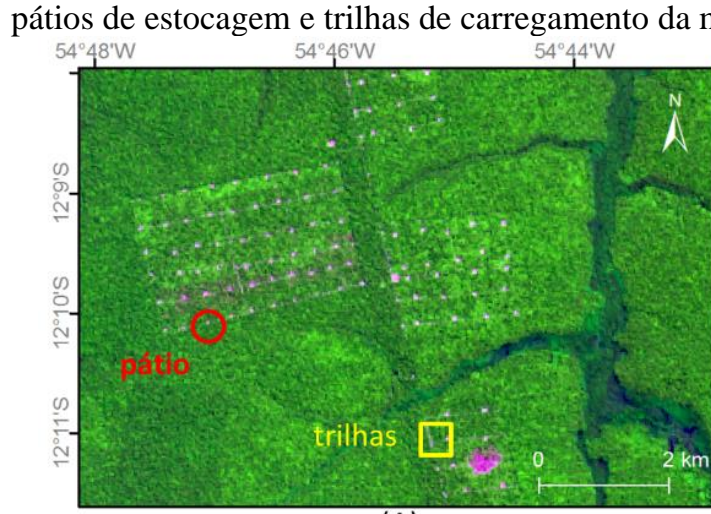

(A)

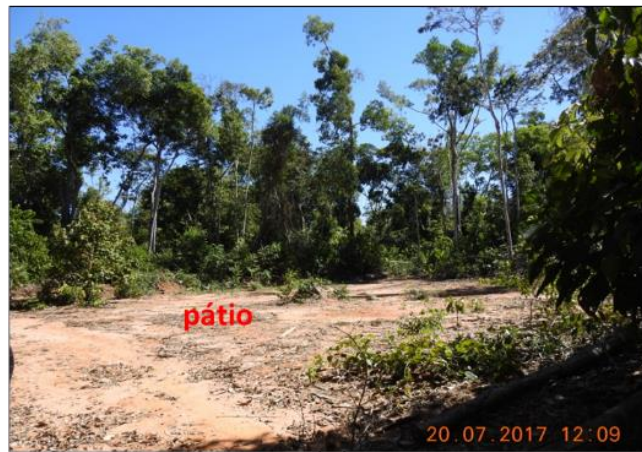

$(C)$

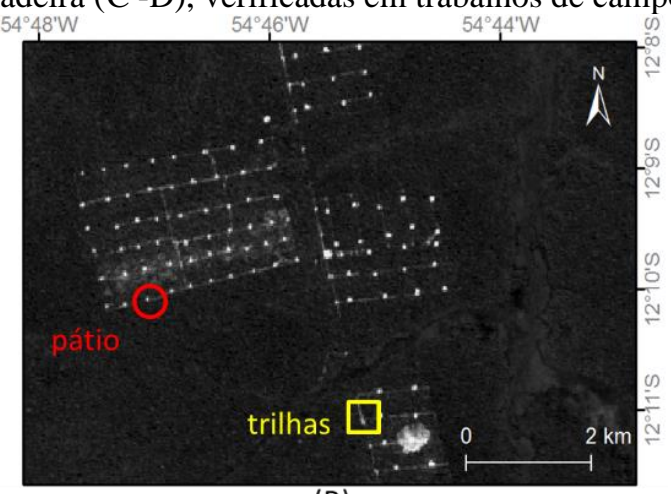

(B)

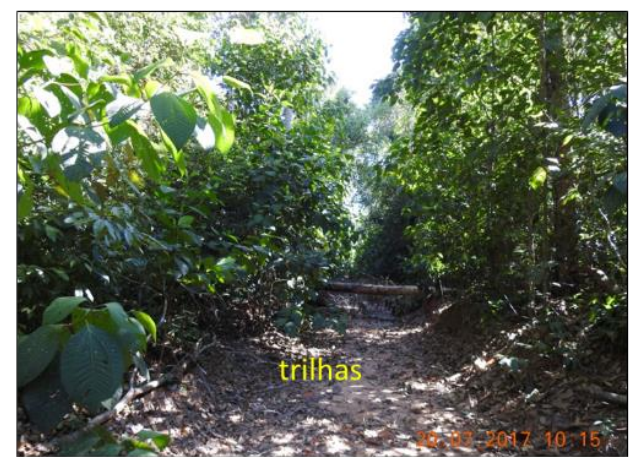

(D)

Fonte: Shimabukuro et al. (2019).

\subsection{Mapeamento de áreas queimadas}

Distúrbios florestais, como o corte seletivo e o fogo, são duas das principais causas de degradação florestal e emissões de carbono na Amazônia. Tais distúrbios induzem mudanças na estrutura florestal, na composição de espécies, nos estoques de biomassa e favorecem à conversão ao desmatamento. Com isso, além da capacidade das imagens frações de utilização para a detecção das áreas desmatadas e corte seletivo, através delas é possível também identificar outro importante tipo de ação antropogênica na cobertura florestal, como é o caso das queimadas.

Para a fase interpretativa inicial das áreas queimadas, utilizando imagens MODIS, por exemplo, informações do Programa de Monitoramento de Queimadas do INPE (INPE, 2020b), que apresenta o monitoramento diário dos pontos críticos, podem ser utilizadas para proporcionar uma base de dados georreferenciada com a localização de vários hot-spots.

A Figura 16A exibe a localização de áreas queimadas no estado do Mato Grosso utilizando uma imagem Landsat, destacando as áreas mapeadas como desmatamento (em amarelo) que são mascaradas com o intuito de detectar áreas queimadas apenas em áreas de floresta. A Figura 16B representa a respectiva imagem individual da fração sombra/água (SHIMABUKURO et al., 2019). As áreas queimadas são identificadas por níveis de cinza mais altos, quando comparadas aos outros alvos na imagem fração sombra/água, facilitando sua discriminação. No entanto, é importante destacar que essas áreas podem ser confundidas com corpos d'agua, sendo necessária a utilização de uma máscara de água para reduzir os erros de inclusão por um método automático ou semi-automático. 
Figura 16 - Parte de uma imagem Landsat no estado do Mato Grosso: exibindo áreas queimadas na floresta (A) e a respectiva imagem de fração sombra/água (B) realçando as áreas de baixa reflectância.

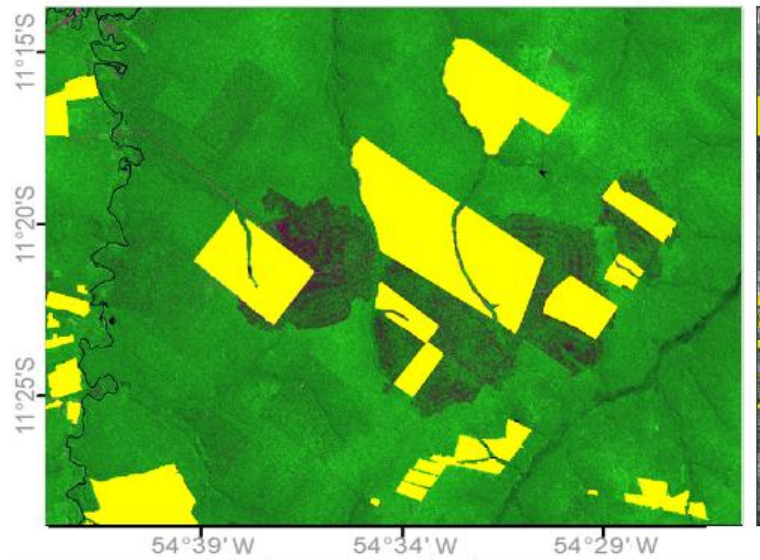

(A)

Áreas desmatadas

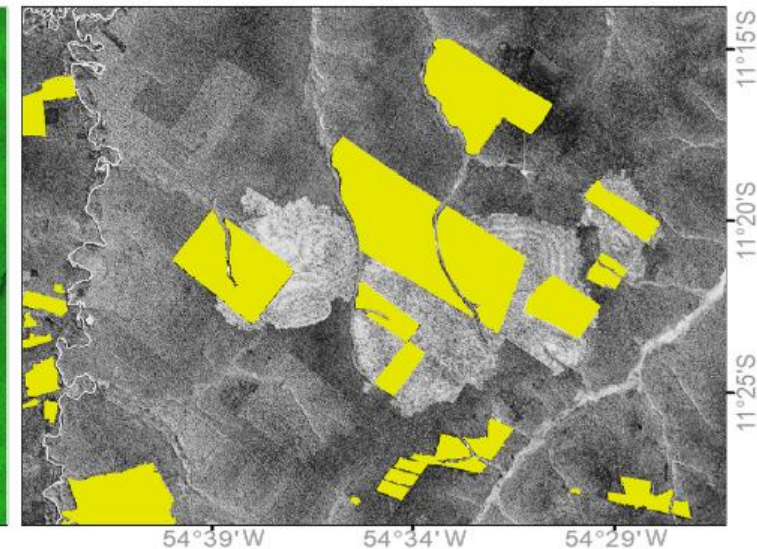

$(B)$

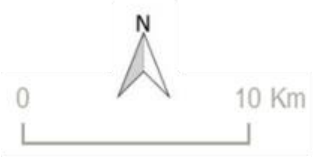

Fonte: Shimabukuro et al. (2019).

Analisando os resultados anuais entre 2005 e 2017 utilizando imagens provenientes dos satélites Landsat, exemplo na Figura 17, os resultados da análise das imagens multitemporais de fração sombra/água indicaram a ocorrência de aproximadamente $957 \mathrm{~km}^{2}$ de novas áreas queimadas em floresta no estado do Mato Grosso, ou seja, áreas de floresta degradada pelo fogo (SHIMABUKURO et al., 2019). Além dessas áreas, há de se considerar também a ocorrência do fogo em áreas previamente desmatadas, onde a atividade de queima serve como uma prática tradicional de limpeza do solo para a implantação de culturas agrícolas ou novas pastagens ou até como uma prática de melhoria das pastagens.

Figura 17 - Áreas queimadas no estado do Mato Grosso identificadas nas imagens provenientes dos sensores TM e OLI da série Landsat adquiridas entre 2005 e 2017.

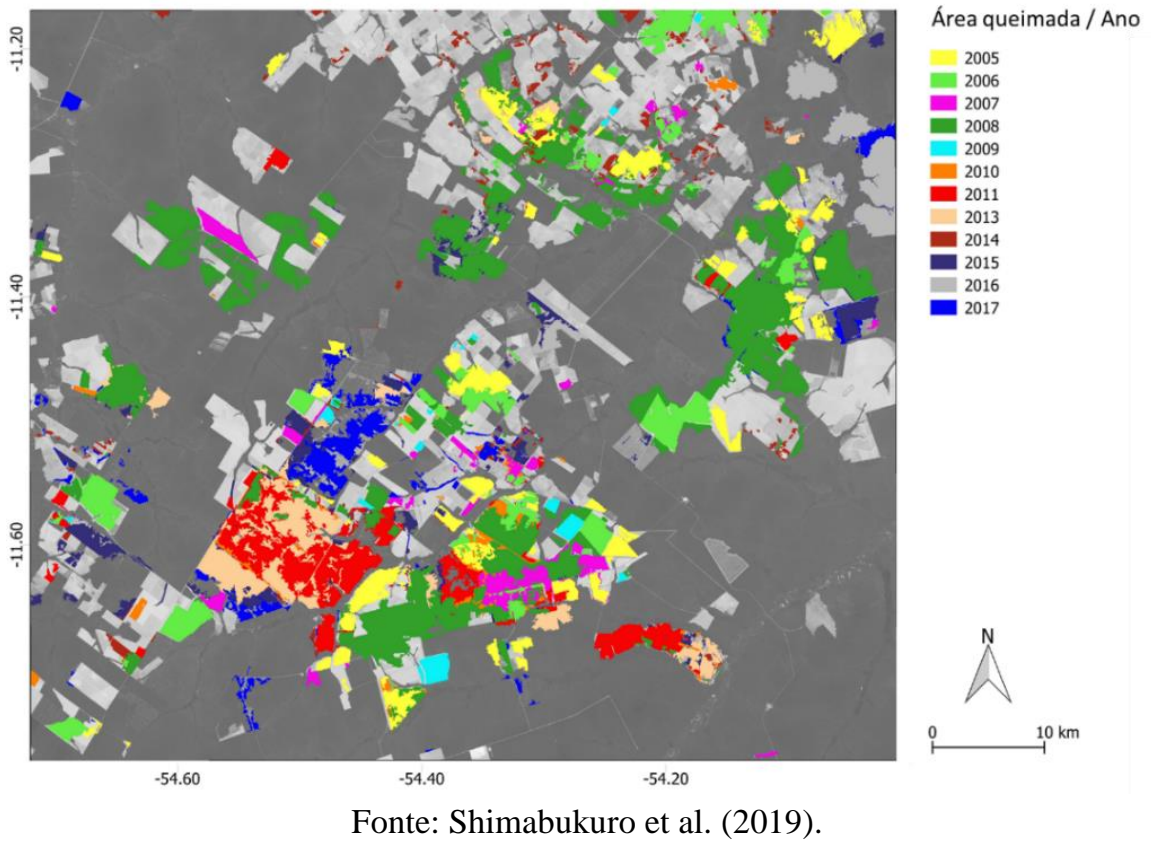

\section{PERSPECTIVAS OPERACIONAIS}

Algumas das aplicações do MLME utilizando as imagens fração derivadas pontualmente no tempo e em escalas local e regional foram explicitadas aqui nesse trabalho. Recentemente, alguns trabalhos têm demonstrado a aplicabilidade do MLME em discriminar diferentes alvos da superfície terrestre em escala 
nacional (SHIMABUKURO et al., 2020) e global (ADAMI et al., 2018) (Figura 18); e, ainda mais recentemente, alguns trabalhos que evidenciam a aplicabilidade do MLME em análises que utilizam as imagens frações derivadas de imagens intranual (ARAI et al., 2020; CASSOL et al., 2020) ou interanual (DUTRA, 2019).

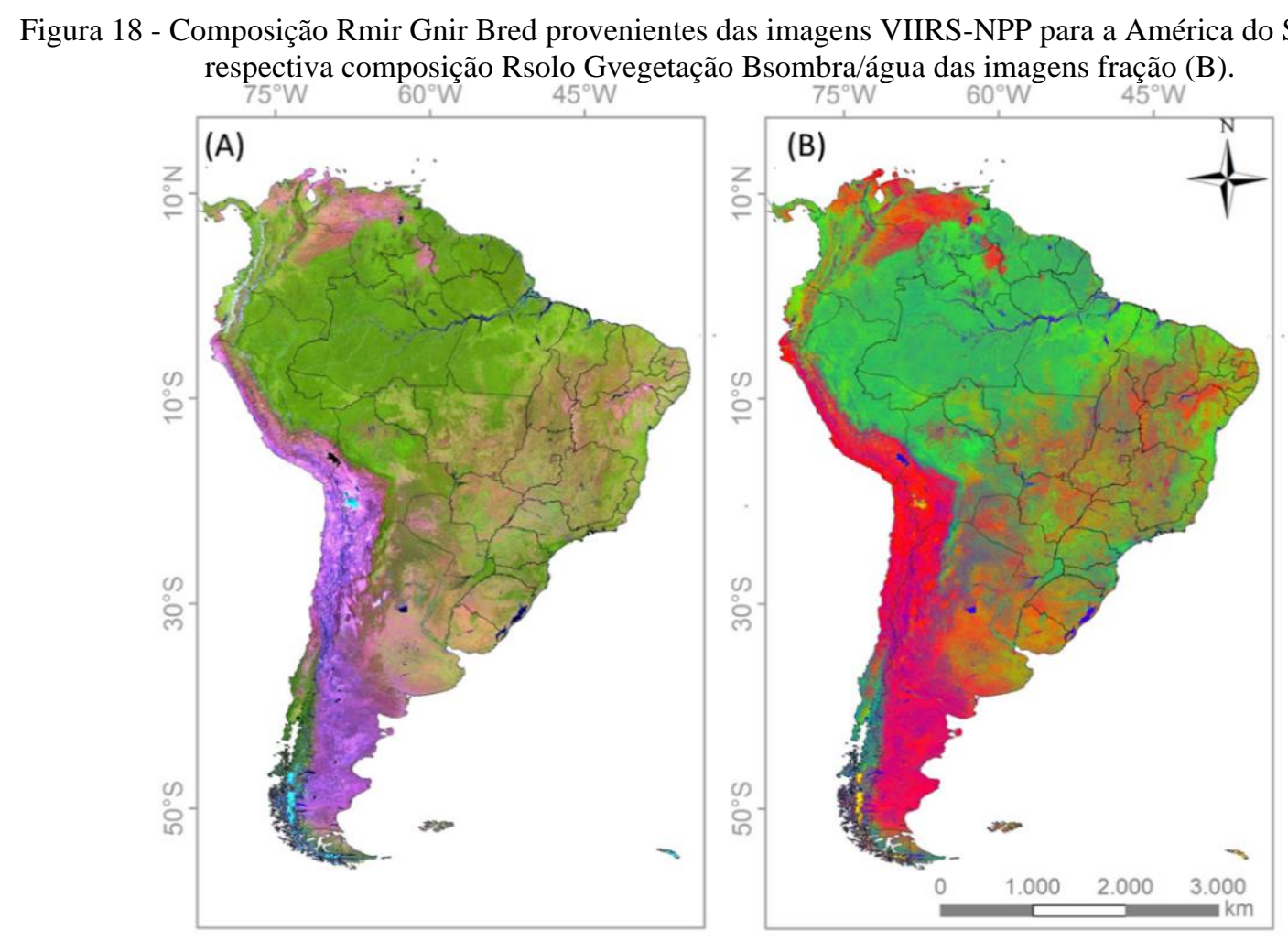

Fonte: Os autores (2020).

Nos últimos anos houve o aumento exponencial no número de imagens disponibilizadas provenientes de sensores remotos e, consequentemente o aumento do número de estudos baseados em análises de séries temporais a partir de amostras selecionadas ao longo de um determinado período no tempo (GALFORD et al., 2008; COUTO Jr. et al., 2012). Tais análises geralmente estão associadas a um grande volume de dados, sendo necessário, portanto, o uso de técnicas que extraiam informações com eficiência ou até mesmo que reduzam a dimensionalidade dos dados sem perdas significativas de informações (BORGES; SANO, 2014). Consideramse também o uso de técnicas que não apresentem redução da sensibilidade em regiões de elevada biomassa (ex: florestas tropicais), e além da contribuição dos efeitos do solo, cujos fatores limitam a aplicação de determinados índices de vegetação (ADAMI et al., 2018).

Desta maneira, as imagens frações resultantes do modelo linear de mistura espectral aplicado em séries temporais possibilitam a quantificação da proporção de cada alvo no espaço-tempo e suas variações. A partir de um conjunto de imagens multitemporais entre 2000 e 2017, Dutra (2019) construiu perfis de séries espaçotemporais das imagens frações de modo a observar as potencialidades dessas imagens para o monitoramento do uso e cobertura da terra. Como exemplo, foram identificadas áreas que apresentaram evidências da degradação em vegetação nativa (Figura 19), bem como o assoreamento de corpos hídricos em períodos caracterizados por eventos climáticos extremos de seca a partir do aumento da proporção da fração solo. 
Figura 19 - Exemplo de perfis temporais produzidos com as imagens fração vegetação, solo e sombra entre 2000 e 2017 sem filtragem de dados e em escala de 0 a 1 aplicado em amostra de degradação da vegetação nativa.

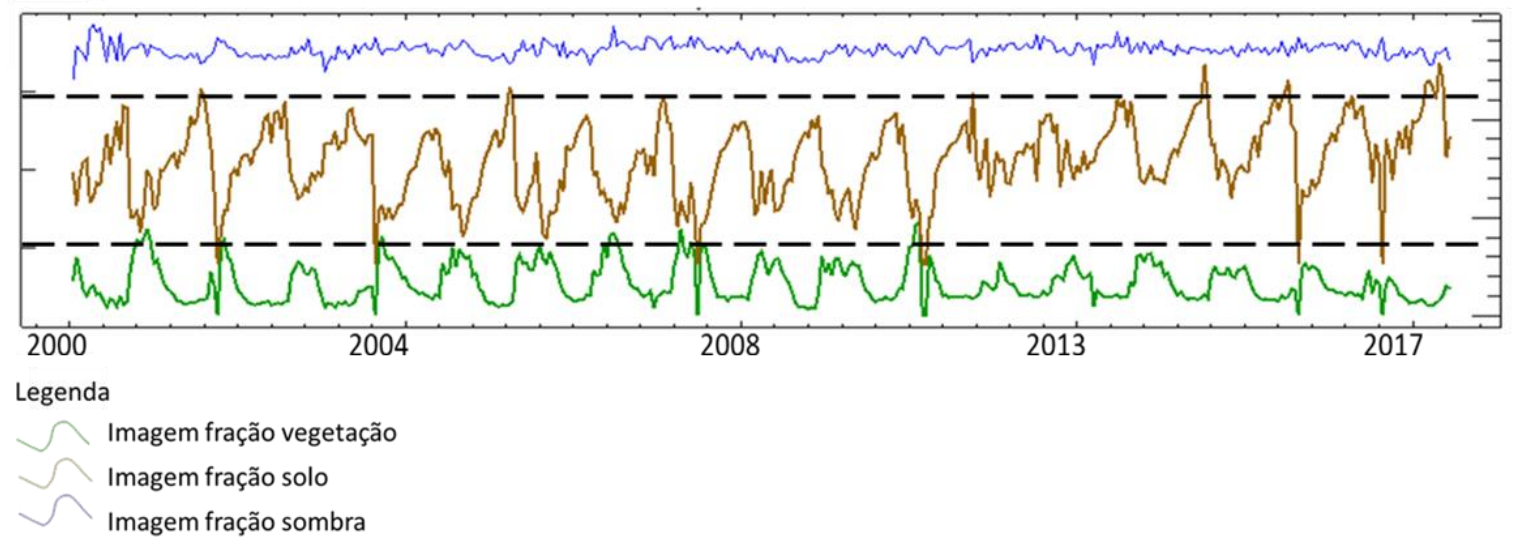

Fonte: Dutra (2019).

Assim, o uso dos perfis temporais das imagens frações demonstram potencialidades para analisar, por exemplo, a relação entre a resposta da vegetação e a influência dos fatores climáticos de precipitação e temperatura nas diferentes fitofisionomias, possibilitando o emprego de análises estatísticas, algoritmos de séries temporais para extração de métricas e atributos de sazonalidade, como por exemplo o TIMESAT (EKLUNDH; JÖNSSON, 2012), além de métodos capazes de detectar quebras de padrão no comportamento das tendências, como o BFAST (Breaks For Additive Seasonal and Trend) (VERBESSELT et al., 2010).

Neste contexto, as aplicações aqui levantadas corroboram nas perspectivas do estabelecimento de uma metodologia em nível operacional para o mapeamento e monitoramento do uso e cobertura da terra e em diferentes escalas geográficas utilizando a aplicação do modelo linear de mistura espectral.

\section{CONCLUSÃO}

A mistura espectral pode ser linear e não linear. O modelo linear foi discutido devido à facilidade de implementação com resultados muito satisfatórios. O modelo linear de mistura espectral é uma técnica de transformação de dados de sensores remoto, ou seja, converte as informações espectrais em informações de proporção física dos componentes dentro do pixel. Esta informação da proporção dos componentes é representada em imagens frações. Dessa forma, o modelo linear de mistura espectral é uma técnica de redução de dados e, além disso, realça as informações desses componentes no pixel da imagem, facilitando processos posteriores de classificação e análises. Não é um classificador temático, mas fornece informações úteis na forma de imagens frações para uma variedade de aplicações em várias áreas de estudo.

Em geral, esses componentes considerados no pixel são vegetação, solo e sombra/água, como os principais elementos presentes na superfície terrestre. A imagem fração vegetação apresenta informações semelhantes aos índices de vegetação como NDVI e EVI, destacando as áreas de cobertura vegetal; a imagem da fração solo destaca as áreas sem cobertura vegetal; e a imagem da fração sombra/água destaca os corpos d'água e as áreas queimadas. Desse modo, as imagens fração vegetação, solo e sombra/água foram importantes para automatizar o projeto PRODES, realizado através do projeto PRODES Digital, fornecendo tanto a estimativa de áreas desmatadas como o mapa de distribuição espacial dessas áreas, bem como o projeto DETER para a identificação em tempo quase real dos distúrbios florestais. Além de outras aplicações relacionadas ao mapeamento de uso e cobertura da terra e distúrbios florestais como o corte seletivo e fogo. A geração de séries temporais das imagens fração podem contribuir para o estabelecimento de uma metodologia em nível operacional para o mapeamento e monitoramento do uso e cobertura da terra, em diferentes escalas geográficas, e em diferentes análises temporais.

A revisão proposta neste trabalho permitiu difundir as informações e o conhecimento adquirido de aplicações passadas, visando possibilitar o preenchimento de lacunas do conhecimento e o aprimoramento ou desenvolvimento de metodologias confiáveis para diversas temáticas de pesquisa no âmbito do sensoriamento remoto, durante esses 50 anos de atuação da Revista Brasileira de Cartografia (RBC). 
Diante desse contexto, surgem os seguintes questionamentos para pesquisas futuras: Quais as possibilidades no desenvolvimento de métodos operacionais abrangentes e confiáveis para o mapeamento e monitoramento na Amazônia Legal Brasileira baseados em dados de sensoriamento remoto? Como as variações nas proporções das imagens fração podem ser observadas para elucidar a caracterização de diferentes alvos na superfície terrestre (ex., regeneração florestal, fitofisionomias, agricultura, corpos hídricos, etc)? Quais componentes podem ser analisados como potenciais endmembers em pesquisas futuras na Amazônia? Considerando a característica de análise a nível de sub-pixel com as imagens fração, é possível obter estimativas mais precisas no cálculo de áreas? Estas são algumas das sugestões em um leque de possibilidades e aplicações no desenvolvimento científico neste campo do conhecimento.

\section{Agradecimentos}

O estudo foi apoiado pela Fundação de Amparo à Pesquisa do Estado de São Paulo (FAPESP Processo 19806-3/2016). Y.E.S. agradece ao Conselho Nacional de Desenvolvimento Científico e Tecnológico (CNPq - Bolsa de Produtividade 303299/2018-5). A.C.D agradece ao Conselho Nacional de Desenvolvimento Científico e Tecnológico (CNPq - Processo 380716/2019-4).

\section{Contribuição dos Autores}

Yosio Shimabukuro, Andeise Dutra e Egidio Arai participaram de todas as etapas deste trabalho de revisão, desde a sua concepção, revisão bibliográfica, preparação de figuras, tabelas, escrita e revisão do manuscrito.

\section{Conflitos de Interesse}

Os autores declaram que não há conflitos de interesse.

\section{Referências}

ACHARD, F.; EVA, H. D.; STIBIG, H. J.; MAYAUX, P.; GALLEGO, J.; RICHARDS, T.; MALINGREAU, J. P. Determination of deforestation rates of the world's humid tropical forests. Science, 297(5583), pp. 999-1002, 2002. DOI: 10.1126/science.1070656.

ADAMI, M.; BERNARDES, S.; ARAI, E.; FREITAS, R.M.; SHIMABUKURO, Y.E.; ESPÍRITO-SANTO, F.D.; RUDORFF, B.F.; ANDERSON, L.O. Seasonality of vegetation types of South America depicted by moderate resolution imaging spectroradiometer (MODIS) time series. International Journal of Applied Earth Observation and Geoinformation, v.69, p.148-163, 2018. DOI: 10.1016/j.jag.2018.02.010.

ADAMS, J. B.; GILLESPIE, A. R. Remote Sensing of Landscapes with Spectral Images: A Physical Modelling Approach, 378 p., 2006. (Cambridge: Cambridge University Press).

ADAMS, J. B.; SABOL, D.; KAPOS, V.; ALMEIDA, R.; ROBERTS, A.; SMITH, M. O.; GILLESPIE, A. R. Classification of multispectral images based on fractions of endmembers: application to land-cover change in the Brazilian Amazon. Remote Sensing of Environment, 52, pp. 137-154, 1995. DOI: 10.1016/00344257(94)00098-8.

ADAMS, J. B.; SMITH, M. O.; JOHNSON, P. E. Spectral mixture modelling: a new analysis of rock and soil types at the Viking Lander I site. Journal of Geophysical Research, 91, pp. 8098-8112, 1986. DOI: 10.1029/JB091iB08p08098.

ALCÂNTARA, E.; BARBOSA, C.; STECH, J.; NOVO, E. M.; SHIMABUKURO, Y. E. Improving the spectral unmixing algorithm to map water turbidity distributions. Environmental Modelling and Software, 24, pp. 1051-1061, 2009. DOI: 10.1016/j.envsoft.2009.02.013.

ANDERSON, L. O.; SHIMABUKURO, Y. E.; DEFRIES, R. S.; MORTON, D. Assessment of deforestation 
in near real time over the Brazilian Amazon using multitemporal fraction images derived from Terra MODIS. IEEE Geoscience and Remote Sensing Letters, 2, pp. 315-318, 2005. DOI: 10.1109/LGRS.2005.850364.

ANWAR, S.; STEIN, A. Detection and Spatial Analysis of Selective Logging with Geometrically Corrected Landsat Images. International Journal of Remote Sensing, 33 (24): 7820-7843, 2012. DOI: 10.1080/01431161.2012.701378.

ASNER, G. P.; KNAPP, D. E.; BROADBENT, E. N.; OLIVEIRA, P. J.; KELLER, M.; SILVA, J. N. Selective logging in the Brazilian Amazon. Science, 310(5747), pp. 480-482, 2005. DOI: 10.1126/science.1118051.

ATKINSON, P.; CUTLER, M.; LEWIS, H. Mapping subpixel proportional land cover with AVHRR imagery. International Journal of Remote Sensing, 18, pp. 917-935, 1997. DOI: 10.1080/014311697218836.

ARAI, E.; SANO, E. E.; DUTRA, A. C., CASSOL, H. L. G.; HOFFMANN, T. B.; SHIMABUKURO, Y. E. Vegetation Fraction Images Derived from PROBA-V Data for Rapid Assessment of Annual Croplands in Brazil. Remote Sensing, 12(7), p.1152, 2020. DOI: 10.3390/rs12071152.

ASSIS, L. F. F. G.; FERREIRA, K. R.; VINHAS, L.; MAURANO, L.; ALMEIDA, C.; CARVALHO, A.; RODRIGUES, J.; MACIEL, A.; CAMARGO, C. TerraBrasilis: A Spatial Data Analytics Infrastructure for Large-Scale Thematic Mapping. ISPRS International Journal of Geo-Information, 8, 513, 2019. DOI: $10.3390 /$ ijgi8110513.

BASTIN, L. Comparison of fuzzy c-means classification, linear mixture modeling and MLC probabilities as tools for unmixing coarse pixels. International Journal of Remote Sensing, 18, pp. 3629-3648, 1997. DOI: $10.1080 / 014311697216847$.

BOARDMAN, J. W. Automating spectral unmixing of AVIRIS data using convex geometry concepts... (In Summaries 4th Annu. JPL Airborne GeoscienceWorkshop), JPL Publication 93-26, vol. 1, pp. 11-14, 1993.

BORGES, E. F.; SANO, E. E.; MEDRADO, E. Radiometric quality and performance of TIMESAT for smoothing moderate resolution imaging spectroradiometer enhanced vegetation index time series from western Bahia State, Brazil. Journal of Applied Remote Sensing, 8(1), p.083580, 2014. DOI: 10.1117/1.JRS.8.083580.

BURDEN, R. L.; FAIRES, J. D.; REYNOLDS, A. C. Numerical analysis. 2. ed. Boston, Massachusetts: Prindle, Weber and Schmidt, 1981.

CASSOL, H. L. G.; ARAI, E.; SANO, E. E.; DUTRA, A. C.; HOFFMANN, T. B.; SHIMABUKURO, Y. E. Maximum Fraction Images Derived from Year-Based Project for On-Board Autonomy-Vegetation (PROBA-V) Data for the Rapid Assessment of Land Use and Land Cover Areas in Mato Grosso State, Brazil. Land, 9(5), p.139, 2020. DOI: 10.3390/land9050139.

COCHRANE, M. A.; ALENCAR, A.; SCHULZE, M. D.; SOUZA JR., C. M.; NEPSTAD, D. C.; LEFEBVRE, P.; DAVIDSON, E. A. Positive Feedbacks on the fire dynamic of closed canopy tropical forests. Science, 284, 1832-1835, 1999. DOI: 10.1126/science.284.5421.1832.

COUTO JUNIOR, A.F.; CARVALHO JUNIOR, O. A.; MARTINS, E. S. Séries temporais MODIS aplicadas em sucessão de culturas de soja (Glycine max (L.) Merrill) e milho (Zea mays L.) em sistema de plantio direto. Revista Brasileira de Cartografia, v. 64, p. 405-418, 2012.

DE FREITAS, R. M.; HAERTEL, V.; SHIMABUKURO, Y. E. Modelo Linear de Mistura Espectral em Imagem de Moderada Resolução Espacial. Boletim de Ciências Geodésicas, v. 14, p. 55-71, 2008.

DETCHMENDY, D.; PACE, W. A model for spectral signature variability for mixtures (Spectral signature variability model based on multispectral band scanner data and clustering experiments, discussing data processing algorithms). Remote Sensing of Earth Resources, p. 596-620, 1972.

DUTRA, A. C. Mapeamento e monitoramento da cobertura vegetal do estado da Bahia utilizando dados multitemporais de sensores ópticos orbitais. Dissertação (Mestrado em Sensoriamento Remoto) Instituto Nacional de Pesquisas Espaciais, São José dos Campos, 2019. 
DUTRA, A. C.; SHIMABUKURO, Y. E.; ARAI, E. Linear spectral mixing model applied in images from PROBA-V sensor: A spatial multiresolution approach. RAEGA —O Espaço Geográfico em Análise, 46, 48-62, 2019. DOI: 10.5380/raega.v46i3.67098.

EKLUNDH, L.; JÖNSSON, P. TIMESAT 3.2 with parallel processing:software manual. Lund: Lund University, 2012. 88p.

FARRAND, W.; SINGER, R.; MERÉNYI, E. Retrieval of apparent surface reflectance from AVIRIS Data: a comparison of empirical line, radiative transfer, and spectral mixture methods. Remote Sensing of Environment, 47, pp. 311-321, 1994. DOI: 10.1016/0034-4257(94)90099-X.

FEARNSIDE, P. M. Deforestation in Brazilian Amazonia: the effect of population and land tenure. AmbioJournal of Human Environment Research and Management, 22(8), pp. 537-545, 1993.

FOODY, G. M.; LUCAS, R. M.; CURRAN, P. J.; HONZAK, M. Non-linear mixture modelling without endmembers using an artificial neural network. International Journal of Remote Sensing, 18(4), p. 937953, 1997. DOI: 10.1080/014311697218845.

GALFORD, G. L.; MUSTARD, J. F.; MELILLO, J.; GENDRIN, A.; CERRI, C. C.; CERRI, C. E. P. Wavelet analysis of MODIS time series to detect expansion and intensification of row-crop agriculture in Brazil. Remote Sensing of Environment, v. 112, p. 576-587, 2008. DOI: 10.1016/j.rse.2007.05.017.

GARCÍA-HARO, F.; SOMMNER, S.; KEMPER, T. A new tool for variable multiple endmember spectral mixture analysis (VMESMA). International Journal of Remote Sensing, 26, pp. 2135-2162, 2005. DOI: 10.1080/01431160512331337817.

GROGAN, J.; JENNINGS, S. B.; LANDIS, R. M.; SCHULZE, M.; BAIMA, A. M.; LOPES, J. D. C. A.; SILVA, J. N. M. What loggers leave behind: Impacts on big-leaf mahogany (Swietenia macrophylla) commercial populations and potential for post-logging recovery in the Brazilian Amazon. Forest Ecology and Management, 255(2), pp. 269-281, 2008. DOI: 10.1016/j.foreco.2007.09.048.

HALLUM, C. R. On a model for optimal proportions estimates for category mixtures. Remote Sensing of Environment, 951, 1972.

HAPKE, B. Theory of Reflectance and Emittance Spectroscopy.(Cambridge, MA: Cambridge University Press), 1993.

HEIMES, F. J. Effects of scene proportions on spectral reflectance in lodgepole pine. (In Doctoral dissertation, Colorado State University), 1977.

HORWITZ, H. M.; NALEPKA, R. F.; HYDE, P. D.; MORGENSTERN, J. P. Estimating the proportions of objects within a single resolution element of a multispectral scanner. Ann Arbor: University of Michigan, Contract NAS-9-9784, 1971.

ICHOKU, C.; KARNIELI, A. A review of mixture modeling techniques for sub-pixel land cover estimation. Remote Sensing Reviews, 13, pp. 161-186, 1996. DOI: 10.1080/02757259609532303.

INPE, 2008. Monitoramento da cobertura florestal da Amazônia por Satélites. Sistemas PRODES, DETER, DEGRAD e QUEIMADAS 2007-2008. INPE, p. 47. Disponível em: http://www.obt.inpe.br/OBT/assuntos/programas/amazonia/deter/pdfs/metodologia_v2.pdf. Acesso em: ago. 2020.

INPE - Instituto Nacional de Pesquisas Espaciais. Coordenação Geral de Observação da Terra. Programa de Monitoramento da Amazônia e Demais Biomas. Desmatamento - Amazônia Legal. Disponível em: http://terrabrasilis.dpi.inpe.br/downloads/. Acessado em: maio 2020.

INPE - Instituto Nacional de Pesquisas Espaciais. Portal do Monitoramento de Queimadas e Incêndios, 2020b. Disponível em http://queimadas.dgi.inpe.br/queimadas/aq1km/. Acesso em: mar. 2020.

KESHAVA, N. A survey of spectral unmixing algorithms. Lincon Laboratory Journal, 14, pp. 55-78, 2003. Disponível em: https://archive.1l.mit.edu/publications/journal/pdf/vol14_no1/14_1survey.pdf. Acesso em: maio 2020.

KESHAVA, N.; MUSTARD, J. F. Spectral unmixing. IEEE Processing Magazine, 2, pp. 44-57, 2002. DOI: 


\subsection{9/79.974727.}

KINTISCH, E. Carbon Emissions: Improved Monitoring of Rainforests Helps Pierce Haze of Deforestation. Science, 316, 5824, p. 536-537, 27 abr. 2007. DOI: 10.1126/science.316.5824.536.

MAHAR, D. J. Deforestation in Brazil's Amazon region: Magnitude, rate and causes. The World Bank, New York, $1988 . \quad$ Disponível em: http://documents1.worldbank.org/curated/en/304691468770373897/pdf/multi-page.pdf. Acesso em: maio 2020.

MATRICARDI, E. A.; SKOLE, D. L.; PEDLOWSKI, M. A.; CHOMENTOWSKI, W.; FERNANDES, L. C. Assessment of tropical forest degradation by selective logging and fire using Landsat imagery. Remote Sensing of Environment, 114(5), pp. 1117-1129, 2010. DOI: 10.1016/j.rse.2010.01.001.

MEYER, T.; OKIN, G. S. Evaluation of spectral unmixing techniques using MODIS in a structurally complex savanna environment for retrieval of green vegetation, nonphotosynthetic vegetation, and soil fractional cover. Remote Sensing of Environment, 161, p. 122-130, 2015. DOI: 10.1016/j.rse.2015.02.013.

MORAN, E. F. Developing the Amazon. Indiana Univ. Press, 1981. DOI: 10.1086/ahr/87.5.1507.

MORAN, E. F. Deforestation and land use in the Brazilian Amazon. Human Ecology, 21(1), pp. 1-21, 1993.

MORAN, E. F.; BRONDIZIO, E.; MAUSEL, P.; WU, Y. Integrating Amazonian vegetation, land-use, and satellite data. BioScience, 44(5), pp. 329-338, 1994.

NEPSTAD, D. C.; KLINK, C. A.; UHL, C.; VIEIRA, I. C.; LEFEBVRE, P.; PEDLOWSKI, M.; HOMMA, A. Land-use in Amazonia and the cerrado of Brazil. Embrapa Amazônia Oriental-Artigo em periódico indexado (ALICE), Ciência e Cultura, São Paulo, v. 49, n. 1/2, p. 73-86, 1997. Disponível em: http://www.alice.cnptia.embrapa.br/alice/handle/doc/1030465. Acesso em: Maio, 2020.

NOVO, E.; SHIMABUKURO, Y. E. Spectral mixture analysis of inland tropical waters. International Journal of Remote Sensing, 15, pp. 1351-1356, 1994. DOI: 10.1080/01431169408954169.

PANIZZA, A. C.; FONSECA, F. P. Técnicas de interpretação visual de imagens. GEOUSP - Espaço e Tempo, São Paulo, 30, pp. 30-43, 2011. DOI: 10.11606/issn.2179-0892.geousp.2011.74230.

PLAZA, A.; MARTÍNEZ, P.; PÉREZ, R.; PLAZA, J. Spatial/spectral endmember extraction by multidimensional morphological operations. IEEE Transactions on Geoscience and Remote Sensing, 40, pp. 2025-2041, 2002. DOI: 10.1109/TGRS.2002.802494

PLAZA, A.; MARTÍNEZ, P.; PÉREZ, R.; PLAZA, J. A quantitative and comparative analysis of endmember extraction algorithms from hyperspectral data. IEEE transactions on geoscience and remote sensing, 42(3), pp. 650-663, 2004. DOI: 10.1109/TGRS.2003.820314.

QUINTANO, C.; FERNÁNDEZ-MANSO, A.; SHIMABUKURO; Y. E.; PEREIRA, G. Spectral unmixing, International Journal of Remote Sensing, 33, 17, 5307-5340, $2012 . \quad$ DOI: 10.1080/01431161.2012.661095.

RANSON, K. J. Computer assisted classification of mixtures with simulated spectral signatures (In Doctoral dissertation, Colorado State University), 1975.

ROBERTS, D. A.; SMITH, M.; ADAMS, J. Green vegetation, nonphotosynthetic vegetation, and soils in AVIRIS data. Remote Sensing of Environment, 44, pp. 255-269, 1993. DOI: 10.1016/00344257(93)90020-X.

ROSIN, P. Robust pixel unmixing. IEEE Transactions on Geoscience and Remote Sensing, 39, pp. 19781983, 2001. DOI: 10.1109/36.951088.

SHIMABUKURO, Y. E. Shade images derived from linear mixing models of multispectral measurements of forested areas. Dissertation (Doctor of Philosophy) - Fort Collins, CO: Colorado State University, 1987.

SHIMABUKURO, Y. E.; SMITH, J. A. The least squares mixing models to generate fraction images derived from remote sensing multispectral data. IEEE Transactions on Geoscience and Remote Sensing, v. 29, n. 1, pp. 16-20, Jan. 1991. DOI: 10.1109/36.103288. 
SHIMABUKURO, Y. E.; SMITH, J. A. Fraction images derived from Landsat TM and MSS data for monitoring reforested areas. Canadian Journal of Remote Sensing, v. 21, n. 1, p. 67-74, 1995. DOI: 10.1080/07038992.1995.10874599.

SHIMABUKURO, Y. E.; BATISTA, G. T.; MELlO, E. M.; MOREIRA, J. C.; DUARTE, V. Using shade fraction image segmentation to evaluate deforestation in Landsat Thematic Mapper images of the Amazon Region. International Journal of Remote Sensing, 19, pp. 535-541, 1998. DOI: /10.1080/014311698216152.

SHIMABUKURO, Y. E.; DUARTE, V.; ANDERSON, L. O.; VALERIANO, D. M.; ARAI, E.; FREITAS, R. M.; RUDORFF, B. F. T.; MOREIRA, M. A. Near real time detection of deforestation in the Brazilian Amazon using MODIS imagery. Ambiente e Água, 1, pp. 37-47, 2006. DOI:10.4136/1980-993X.

SHIMABUKURO, Y.E.; ARAI, E.; DUARTE, V.; JORGE, A.; SANTOS, E. G. D.; GASPARINI, K. A. C.; DUTRA, A. C. Monitoring deforestation and forest degradation using multi-temporal fraction images derived from Landsat sensor data in the Brazilian Amazon. International Journal of Remote Sensing, 40(14), pp. 5475-5496, 2019. DOI: 10.1080/01431161.2019.1579943.

ShIMABUKURO, Y.E.; ARAI, E.; DUARTE, V.; DUTRA, A. C.; CASSOL, H. L. G.; SANO, E. E.; HOFFMANN, T. B. Discriminating Land Use and Land Cover Classes in Brazil Based on the Annual PROBA-V $100 \mathrm{~m}$ Time Series. IEEE Journal of Selected Topics in Applied Earth Observations and Remote Sensing, vol. 13, pp. 3409-3420, 2020. DOI: 10.1109/JSTARS.2020.2994893.

SHIMABUKURO, Y. E.; PONZONI, F. J. Mistura Espectral: modelo linear e aplicações. Oficina de Textos, 2017.

SKOLE, D. L.; CHOMENTOWSKI, W. H.; SALAS, W. A.; NOBRE, A. D. Physical and human dimensions of deforestation in Amazonia. BioScience, 44(5), pp. 314-322, 1994. DOI: 10.2307/1312381.

SKOLE, D.; TUCKER, C. Tropical deforestation and habitat fragmentation in the Amazon: satellite data from 1978 to 1988. Science, 260(5116), pp. 1905-1910, 1993. DOI: 10.1126/science.260.5116.1905.

SMITH, M. O.; JOHNSON, P. E.; ADAMS, J. B. Quantitative determination of mineral types and abundances from reflectance spectra using principal components analysis. Journal of Geophysical Research, 90, pp. 797-804, 1985. DOI: 10.1029/JB090iS02p0C797.

SOUZA JR, C. M.; ROBERTS, D. A.; COCHRANE, M.A. Combining spectral and spatial information to map canopy damage from selective logging and forest fires. Remote Sensing of Environment, 98, 329-343, 2005. DOI: g/10.1016/j.rse.2005.07.013.

TARDIN, A. T.; LEE, D. C. L.; SANTOS, R. J. R.; OSSIS, O. R.; BARBOSA, M. D. S.; MOREIRA, M. D. L.; SANTOS FILHO, C. P. Subprojeto desmatamento. IBDF/CNPq-INPE, Instituto de Pesquisas Espaciais, São José dos Campos, Brazil, 1980.

VERBESSELT, J.; HYNDMAN, R.; NEWNHAM, G.; CULVENOR, D. Detecting trend and seasonal changes in satellite image time series. Remote Sensing of Environment, n. 114, p. 106-115, 2010. DOI: 10.1016/j.rse.2009.08.014.

WHITE, K.; LIVINGSTONE, I.; GURNEY, S.; DEARING, J.; BATEMAN, M. Postprocessing of mineral mixture maps for mapping surficial materials: the example of the Matmata loess, southern Tunisia. International Journal of Remote Sensing, 23, pp. 3091-3106, 2002. DOI: 10.1080/01431160110104674.

WU, C.; MURRAY, A. T. Estimating impervious surface distribution by spectral mixture analysis. Remote Sensing of Environment, 84, pp. 493-505, 2003. DOI: 10.1016/S0034-4257(02)00136-0.

YANG, C.; EVERITT, J. H.; BRADFORD, J. M. Airborne hyperspectral imagery and linear spectral unmixing for mapping variation in crop yield. Precision Agriculture, 8, pp. 279-296, 2007. DOI: 10.1007/s11119007-9045-x. 


\section{Biografia dos Autores}
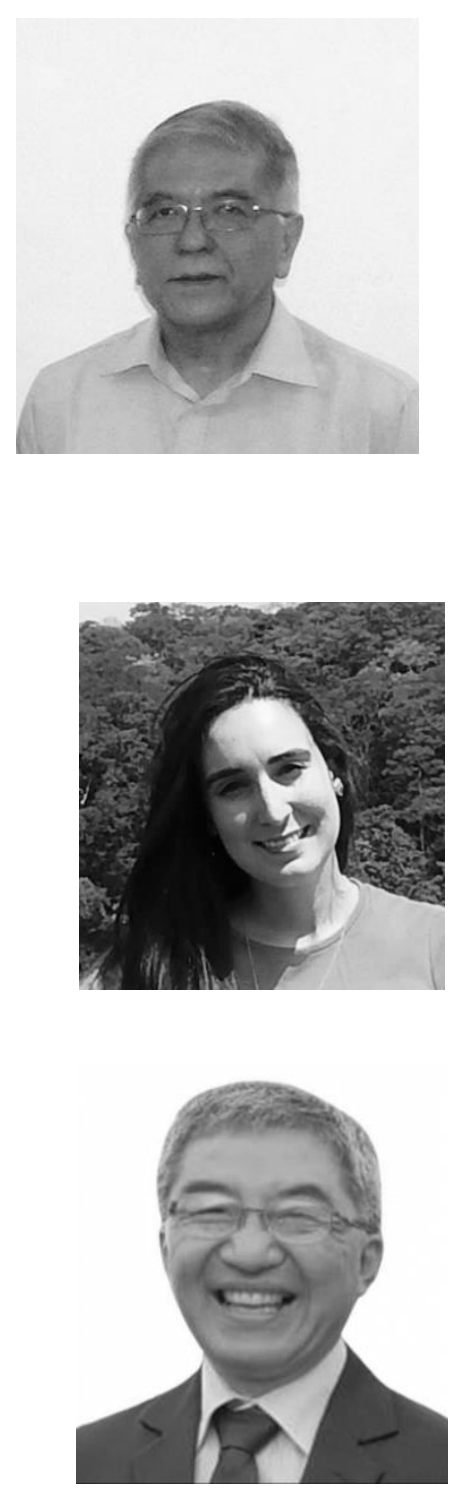

Yosio Edemir Shimabukuro recebeu o BSc em Engenharia Florestal pela Universidade Federal Rural do Rio de Janeiro (UFRRJ) em 1972; MSc em Sensoriamento Remoto pelo Instituto Nacional de Pesquisas Espaciais (INPE) em 1977; e PhD pela Colorado State University, EUA em 1987. De janeiro de 1992 a março de 1994, foi pesquisador visitante no Goddard Space Flight Center da NASA, EUA. Desde 1973, está no INPE, utilizando dados de sensoriamento remoto por satélite e terrestre para análise de cobertura vegetal. Vem aplicando técnicas e modelos de sistema de informação geográfica e sensoriamento remoto para detecção de mudanças ambientais em diferentes biomas do Brasil. É pesquisador 1A do Conselho Nacional de Desenvolvimento Científico e Tecnológico CNPq.

Andeise Cerqueira Dutra nasceu na Bahia. Recebeu o BSc em Engenharia Florestal pela Universidade Federal do Recôncavo da Bahia (UFRB) em 2017 e o MSc em Sensoriamento Remoto pelo Instituto Nacional de Pesquisas Espaciais (INPE) em 2019. Atualmente é bolsista do Conselho Nacional de Desenvolvimento Científico e Tecnológico (CNPq) no projeto Sistema de Risco de Incêndio do Bioma Cerrado (SIRI). Seus interesses de pesquisa são fenologia das espécies, mudanças de uso e cobertura da terra, e monitoramento da vegetação em diferentes biomas no Brasil utilizando técnicas de sensoriamento remoto e sistema de informações geográficas.

Egidio Arai recebeu o curso de Tecnólogo em Processamento de Dados pela Universidade de Taubaté (UNITAU), Taubaté, em 1986, MSc em Computação Aplicada, em 2002 e Doutorado em Sensoriamento Remoto em 2011 pelo Instituto Nacional de Pesquisas Espaciais (INPE), São José dos Campos, Brasil. Atualmente é Tecnologista Sênior no INPE. Seus interesses são ciência da computação e sensoriamento remoto, atuando nos seguintes assuntos: processamento de imagens, séries temporais de imagens, ecossistemas tropicais e ciências ambientais, recursos florestais e sistemas de computador. 